\title{
The role, mechanism and potentially therapeutic application of microRNA-29 family in acute myeloid leukemia
}

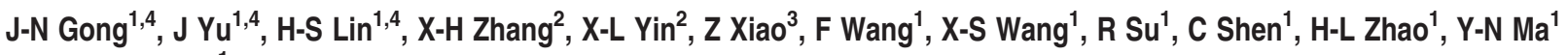 \\ and J-W Zhang,
}

\begin{abstract}
Abnormal proliferation, apoptosis repression and differentiation blockage of hematopoietic stem/progenitor cells have been characterized to be the main reasons leading to acute myeloid leukemia (AML). Previous studies showed that miR-29a and miR-29b could function as tumor suppressors in leukemogenesis. However, a comprehensive investigation of the function and mechanism of miR-29 family in AML development and their potentiality in AML therapy still need to be elucidated. Herein, we reported that the family members, miR-29a, $-29 b$ and $-29 c$, were commonly downregulated in peripheral blood mononuclear cells and bone marrow (BM) CD34 + cells derived from AML patients as compared with the healthy donors. Overexpression of each miR-29 member in THP1 and NB4 cells markedly inhibited cell proliferation and promoted cell apoptosis. AKT2 and CCND2 mRNAs were demonstrated to be targets of the miR-29 members, and the role of miR-29 family was attributed to the decrease of Akt2 and CCND2, two key signaling molecules. Significantly increased Akt2, CCND2 and c-Myc levels in the AML cases were detected, which were correlated with the decreased miR-29 expression in AML blasts. Furthermore, a feed-back loop comprising of c-Myc, miR-29 family and Akt2 were found in myeloid leukemogenesis. Reintroduction of each miR-29 member partially corrected abnormal cell proliferation and apoptosis repression and myeloid differentiation arrest in AML BM blasts. An intravenous injection of miR-29a, $-29 b$ and $-29 c$ in the AML model mice relieved leukemic symptoms significantly. Taken together, our finding revealed a pivotal role of miR-29 family in AML development and rescue of miR-29 family expression in AML patients could provide a new therapeutic strategy.
\end{abstract}

Cell Death and Differentiation (2014) 21, 100-112; doi:10.1038/cdd.2013.133; published online 27 September 2013

Acute myeloid leukemia (AML) is a malignant hematopoietic neoplasm characterized by myeloid differentiation arrest and rapid growth and apoptosis repression of tumor cells that arise from the hematopoietic stem/progenitor cell (HSPC) population within the bone marrow (BM). ${ }^{1}$ The high incidence of $A M L$ was found in many countries. ${ }^{2}$ The French-American-British (FAB) classification system divides AML into eight subtypes, from $M 0$ to $M 7$, and $A M L$ cases involving the monocytic and granulocytic lineage (M1-M5 subtypes) account for $90 \%$ of adult patients. ${ }^{3}$

In the past three decades, great progress has been made in $\mathrm{AML}$ treatment as for the involvement of novel agents and allogeneic stem cell transplantation. ${ }^{4,5}$ However, the overall survival is not optimistic, especially for the older patients. ${ }^{6,7}$ Recent studies on the pathogenesis of AML showed that genetic disorder had the most important role in determining the response to chemotherapy and outcomes, which lead to the incorporation of targeted therapy into the standard treatment and open a new exciting era in AML therapy. Emerging agents include Gemtuzumab ozagamicin-targeting $\mathrm{CD}_{3}{ }^{8}{ }^{8}$ histone deacetylase ${ }^{9,10}$ and proteosome inhibitors, ${ }^{11}$ antiangiogenesis agents, ${ }^{12}$ Fms-like tyrosine kinase 3 inhibitors ${ }^{9,13,14}$ and so on.

MicroRNAs (miRNAs) are small non-coding RNAs that negatively regulate gene expression in the posttranscriptional level, ${ }^{15-17}$ which have been identified as crucial regulators in normal and malignant biological processes. ${ }^{17-24}$ Therefore, the identification of these deregulated miRNAs and their responsive targets may provide potential biomarkers for cancer diagnostics and therapeutic targets in cancer therapy.

MiR-29 family is among the most studied miRNAs. It contains three members, miR-29a, $-29 b$ and $-29 c$. The sequences of mature miR-29 members are highly homologous and contain the same 'seed sequence'. MiR-29s mainly function as tumor suppressors in mantle cell lymphoma, ${ }^{25}$ hepatocellular carcinoma, ${ }^{26,27}$ leukemia, ${ }^{28-30}$ lung cancer, ${ }^{31}$ and so on. However, miR-29 members could

\footnotetext{
${ }^{1}$ Key State Laboratory of Medical Molecular Biology, Department of Biochemistry and Molecular Biology, Institute of Basic Medical Sciences, Chinese Academy of Medical Sciences and Peking Union Medical College, Beijing, China; ${ }^{2}$ Department of Hematology, The 303 Hospital, Nanning, Guangxi, China and ${ }^{3}$ Department of Hematology, The Affiliated Hospital of Inner Mongolia Medical College, Huhehaote, China

${ }^{*}$ Corresponding author: J-W Zhang, Key State Laboratory of Medical Molecular Biology, Department of Biochemistry and Molecular Biology, Institute of Basic Medical Sciences, Chinese Academy of Medical Sciences and Peking Union Medical College, 5 Dong Dan San Tiao, Beijing 100005, China. Tel: +86 10 69156423; Fax: + 8610 65240529; E-mail: junwu_zhang@pumc.edu.cn

${ }^{4}$ These authors contributed equally to this work.

Keywords: acute myeloid leukemia; cell proliferation and apoptosis; miR-29 family; diagnostic markers; therapeutic targets

Abbreviations: AML, acute myeloid leukemia; BM, bone marrow; HSPC, hematopoietic stem/progenitor cell; miR, microRNA; ORF, open reading frame; PBMNCs, peripheral blood mononuclear cells; ROC, receiver-operating characteristic; UTR, untranslated region

Received 26.2.13; revised 04.7.13; accepted 16.8.13; Edited by H Ichijo; published online 27.9.13
} 
also promoted cell migration and invasion and repressed cell apoptosis in breast cancer cells and hepatoma cells. ${ }^{32,33}$ In AML, miR-29a and miR-29b but not miR-29c were reported to be downregulated in AML patients with monosomy $7,{ }^{28}$ and our previous work showed that miR-29a was markedly downregulated in AML patients ignoring AML subtypes. ${ }^{30,34}$ Despite the high similarity of mature $\mathrm{miR}-29 \mathrm{a} / \mathrm{b} / \mathrm{c}$ sequence, several studies showed that different isoforms of miR-29 family could execute distinct functions. ${ }^{35,36}$ Therefore, a comprehensive study of miR-29s' functions, mechanisms and their potentiality in AML therapy is still needed.

Herein, we demonstrated that the miR-29 family members were coincidently downregulated in AML patients and function as tumor suppressors by regulating cell proliferation and apoptosis via targeting AKT2 and CCND2 mRNAs. Ectopic implantation of miR-29s into the AML model mice relieved leukemic symptom apparently. Our results strengthened the understanding of the function and mechanism of miR-29 family in AML development and further demonstrated their potentiality in AML therapy.

\section{Results}

Expression of all the miR-29 family members is markedly downregulated in AML patients. We firstly performed Taqman stem-loop RT-PCR in peripheral blood mononuclear cells (PBMNCs) derived from 81 newly diagnosed AML patients (M1-M5 subtypes) and 93 normal controls to analyze the expression patterns of miR-29s. The specificity of the Taqman probes and primers for detecting miR-29a, $-29 b$ and -29 c was confirmed (Supplementary Figure S1). We observed similar tendency of expression change, that is, a significantly decreased expression of miR-29a, $-29 b$ and $-29 \mathrm{c}$ was detected in AML samples as compared with the healthy donors (Figure 1a). No significant difference of the miRNA expression was detected among the different AML subtype groups and patients with different chromosomal and molecular abnormalities. Receiver-operating characteristic (ROC) curve analysis suggested that expression levels of all the three miRNAs could be as markers with high sensitivity and specificity for AML diagnosis (Figure 1b).

MiR-29s are involved in regulation of cell proliferation and apoptosis. As differentiation blockage, abnormal cell proliferation and apoptosis repression are the key reasons that result in carcinogenesis and an important role of miR$29 \mathrm{a}$ in myeloid differentiation had been demonstrated, ${ }^{34}$ we wanted to examine whether each miR-29 member could affect cell proliferation and apoptosis in myeloid cells. We transfected miR-29a, -29b, -29c and control mimic into THP1 and NB4 cells and measured the percentage of living cells at $0,24,48,72$ and $96 \mathrm{~h}$ and the apoptosis cells at $72 \mathrm{~h}$ after transfection. The results showed that over-presence of any a miR-29 family member was able to inhibit cell proliferation at a great extent (Figure 2a) and induce early and late apoptosis in both THP1 and NB4 cells (Figures 2b and c).

AKT2 and CCND2 are common targets of the miR-29 family members. Using three online softwares: TargetScan, miRanda and PicTar, we identified several potential targets of miR-29 family (data not shown). Among these genes, we chose AKT2 and CCND2 for further study, because of their critical roles in promoting cancer development. There are two putative binding sites in their $3^{\prime}$ UTRs (untranslated regions) (Figure 2d). To test whether the miR-29 members were able to regulate $A K T 2$ and $C C N D 2$ directly, we firstly performed dual luciferase reporter experiments and found that the luciferase activity of AKT2_WT and CCND2_WT was remarkably reduced after transfection with miR-29a, $-29 b$ or -29 c mimic for $36 \mathrm{~h}$. However, single mutation and double mutations
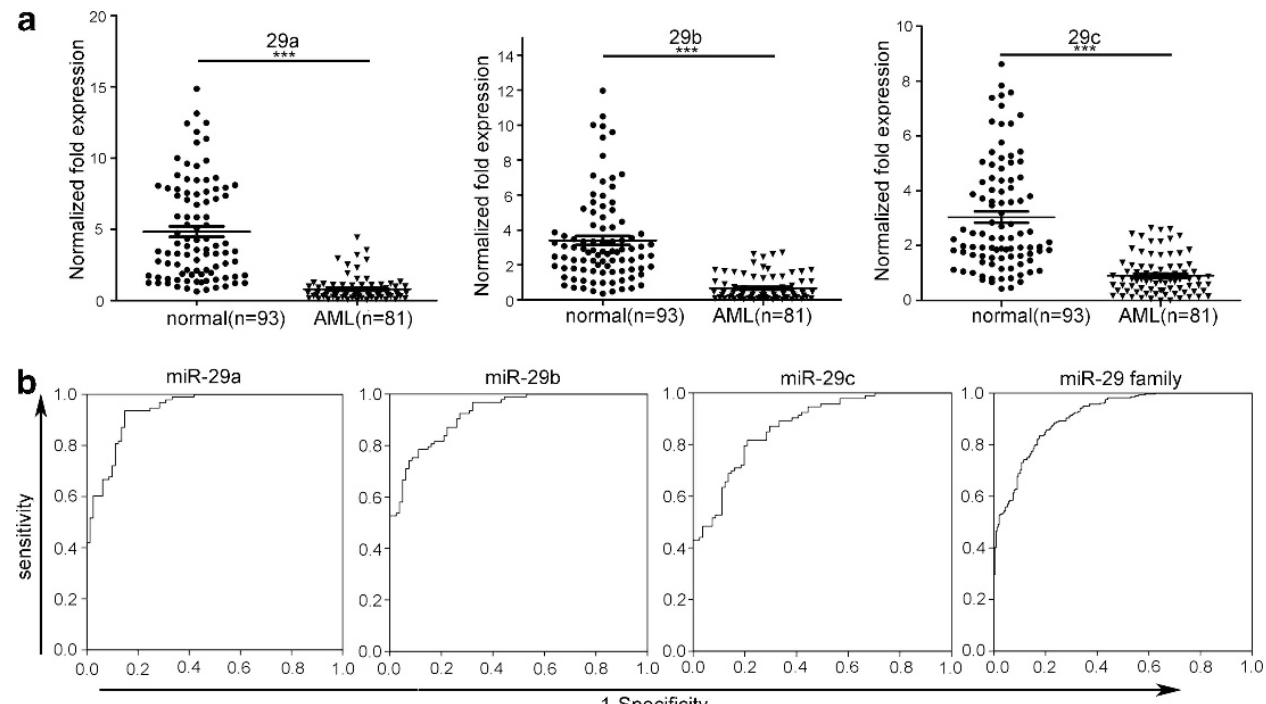

Figure 1 Significantly decreased miR-29s expression was detected in AML patients. (a) The expression of miR-29a, -29b and -29c in PBMNCs derived from 93 healthy donors and 81 AML patients were detected by Taqman stem-loop RT-PCR, and U6 snRNA was used as the internal control. Each real-time PCR assay was performed in triplicate. One common sample was detected in every real-time PCR operation to eliminate the errors among different plates. ${ }^{* * *} P<0.0001$. (b) ROC curve analysis of miR-29a, -29b and -29c expression in patients. The AUC, sensitivity and specificity were: $0.940,0.935$ and 0.852 for miR-29a; $0.924,0.871$ and 0.778 for miR-29b; 0.874 , 0.871 and 0.704 for miR-29c; $0.912,0.885$ and 0.765 for miR-29s, respectively 
a
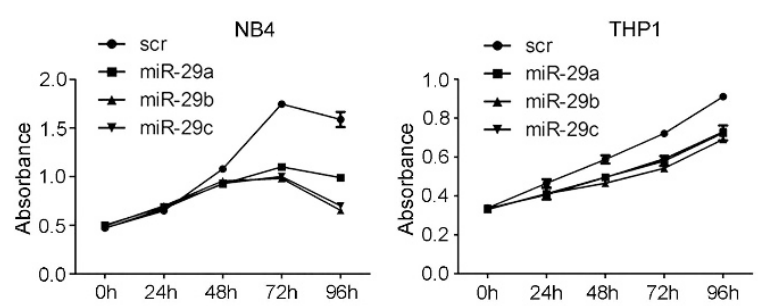

d

AKT2 3'UTR position 3242-3248 position 3511-3517

hsa-miR-29a: 3' AUUggcuaAagucuaccacGau 5' 3' AUUggcuaAagucuaccacGau 5 AKT2 WT $55^{\prime} . .$. GTACTCATTTTGGTGCTGATTACT …………...TTTCGTTTGGTGCTACCAGCAGTC... $3^{3}$ AKT2 M-1 5....GTACTCATTTACCACGAGATTACT ................TTTCGTTTGGTGCTACCAGCAGTC .... AKT2_M-2 $55^{\prime} . .$. GTACTCATTTTGGTGCTGATTACT ....................TTTCGTTACCACGACCAGCAGTC.... $3^{\prime}$ AKT2_dM $55^{5} \ldots$... GTACTCATTTACCACGAGATTACT .................TTTCGTTACCACGACCAGCAGTC....3

CCND2 3'UTR position 906-912 position $\boldsymbol{\gamma}^{2259-2565}$

hsa-miR-29a:3' AUUGgCUAAAGUCUACCACGAU 5' 3' AUUgGCUAAAguCUACCACGAU $55^{\circ}$

CCND2_WT 5'...ACUAAUUUUUGGUGCUGAUUGGAU.............. GUUUAUGGUGCUUCCUUCUCC....3 CCND2_M-1 5'...ACUAAUUUUACCACGAGAUUGGAU..................GUUUAUGGUGCUUCCUUCUCC.... CCND2_M-2 5'...ACUAAUUUUUGGUGCUGAUUGGAU............... GUUUAACCACGAUCCUUCUCC...3 CCND2_dM 5'...ACUAAUUUUACCACGAGAUUGGAU................. GUUUAACCACGAUCCUUCUCC....

b

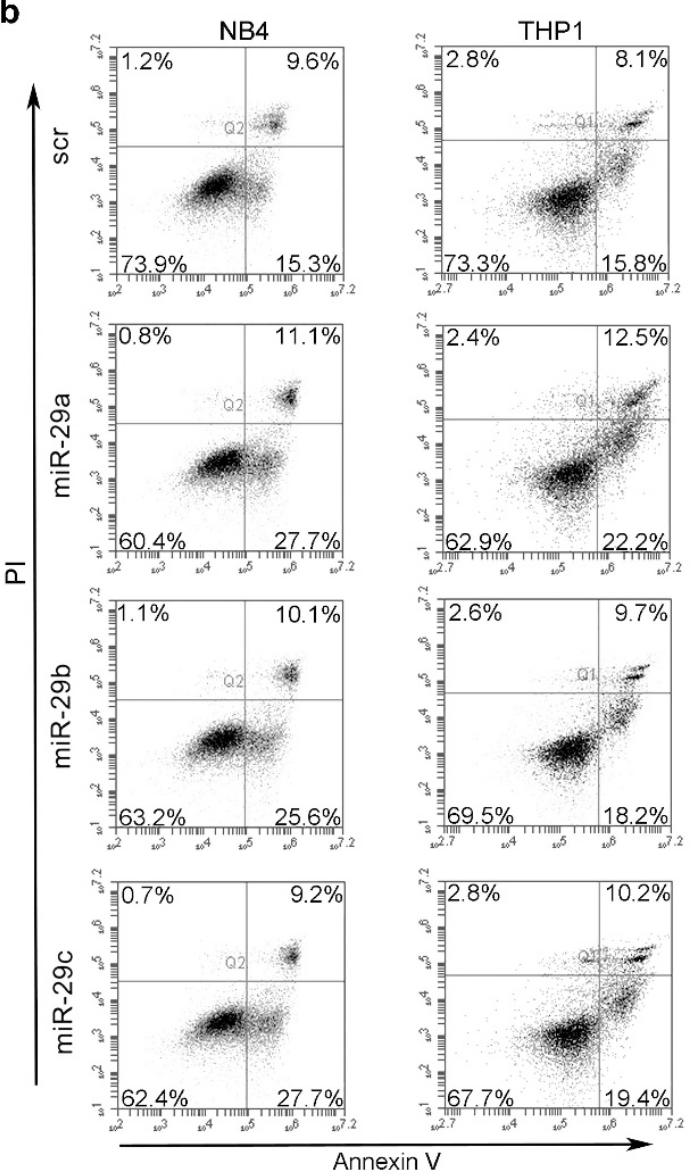

C
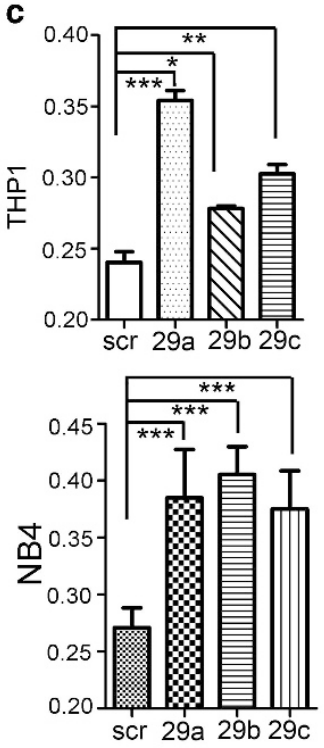

e
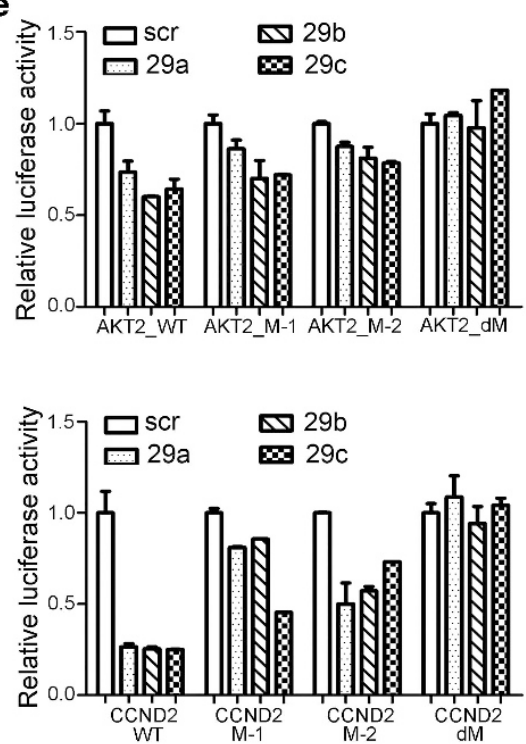

$\mathbf{f}$
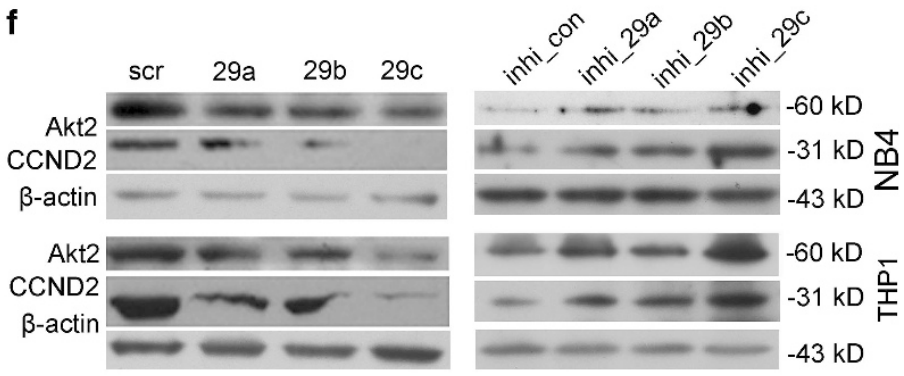

Figure 2 Each miR-29 member inhibits cell proliferation and induces cell apoptosis and AKT2 and CCND2 are validated as targets of miR-29 family in the AML cell lines. (a) Cell grow curve of THP1 and NB4 transfected with miR-29a, $-29 \mathrm{~b},-29 \mathrm{c}$ or control mimic. The results were shown as mean \pm S.D. of three independent experiments. (b) Annexin V/PI assays in THP1 and NB4 after transfection with the mimics for $72 \mathrm{~h}$. The lower-left region represents the living cells, the lower-right region represents cells in early apoptosis and the upper-right region represents the late apoptotic cells or dead cells. (c) Statistical analysis of the percentage of Annexin V-positive cells in the cells transfected with miR-29a, $-29 \mathrm{~b}$ or $-29 \mathrm{c}$ versus that in the cells transfected with control mimic (scr). Data are the average of three independent experiments \pm S.D. ${ }^{*} P<0.05$; ${ }^{* *} P<0.01 ;{ }^{* \star *} P<0.0001$. (d) The nucleotide sequences of miR-29a, the predicted binding sites of miR-29 members and the mutated nucleotides (underlined) in the $3^{\prime} U T R$ of AKT2 and CCND2 were shown. (e) Dual luciferase activity in the transfected 293T cells. The results were shown as mean \pm S.D. of three separated experiments. (f) Immunoblotting of Akt2 and CCND2 in THP1 and NB4 after transfection with miR-29s mimics or their inhibitors for $48 \mathrm{~h}$

abolished the repression by each miR-29 member partially or completely, indicating that miR-29 family could specifically target their binding sites in the $3^{\prime} U T R s$ of $A K T 2$ and CCND2 (Figure 2e).

We next observed significantly decreased expression of the endogenous $A K T 2$ and $C C N D 2$ in two myeloid leukemia cell lines, THP1 and NB4, at both protein (Figure 2f, left) and mRNA levels (Supplementary Figure S2), after transfection with miR-29a, $-29 b$ or $-29 \mathrm{c}$ mimic for $48 \mathrm{~h}$. Furthermore, increased protein levels of both targets were detected when knockingdown the endogenous miR-29a, $-29 \mathrm{~b}$ and $-29 \mathrm{c}$ expression through miRNA inhibitors (Figure 2f, right).

The above results demonstrated AKT2 and CCND2 as the common target genes of the miR-29s in THP1 and NB4 cells.

MiR-29s regulate cell proliferation and apoptosis through targeting $A K T 2$ and CCND2 mRNAs. To test whether the regulation of cell proliferation and apoptosis by 
miR-29s was mediated through Akt2 and CCND2 directly, we firstly transfected siRNAs that specifically interfere in AKT2 or CCND2 expression in both THP1 and NB4 cells and confirm that the knockdown of either AKT2 or CCND2 could reduce cell proliferation and promote cell apoptosis (Supplementary Figure S3).

Then we performed rescue experiments by transfection of 3'-UTR-negative AKT2 and CCDN2 together with miR-29. As expected, transfection with the pcDNA3.1_AKT2 (or pcDNA3.1_CCND2) alleviated the reduction of Akt2 and CCND2 protein levels resulted from miR-29b mimic treatment (Figure 3a). In agreement with the expression of target proteins, transfection with the pcDNA3.1_AKT2 (or pcDNA3.1_CCND2) mitigated the inhibition of cell amplification (Figure $3 \mathrm{~b}$ ) and the increase of apoptotic cells (Figure 3c) resulted from miR-29 mimic treatment.

We also performed rescue experiments by transfection with the combination of AKT2 siRNA (or CCND2 siRNA) and miR-29a inhibitor (or miR-29c inhibitor) in THP1 cells. The results showed that transfection with $A K T 2$ siRNA (or CCND2 siRNA) mitigated the increase of cell amplification and the decrease of apoptotic cells resulted from miR-29 inhibitor treatment (Supplementary Figure 4).
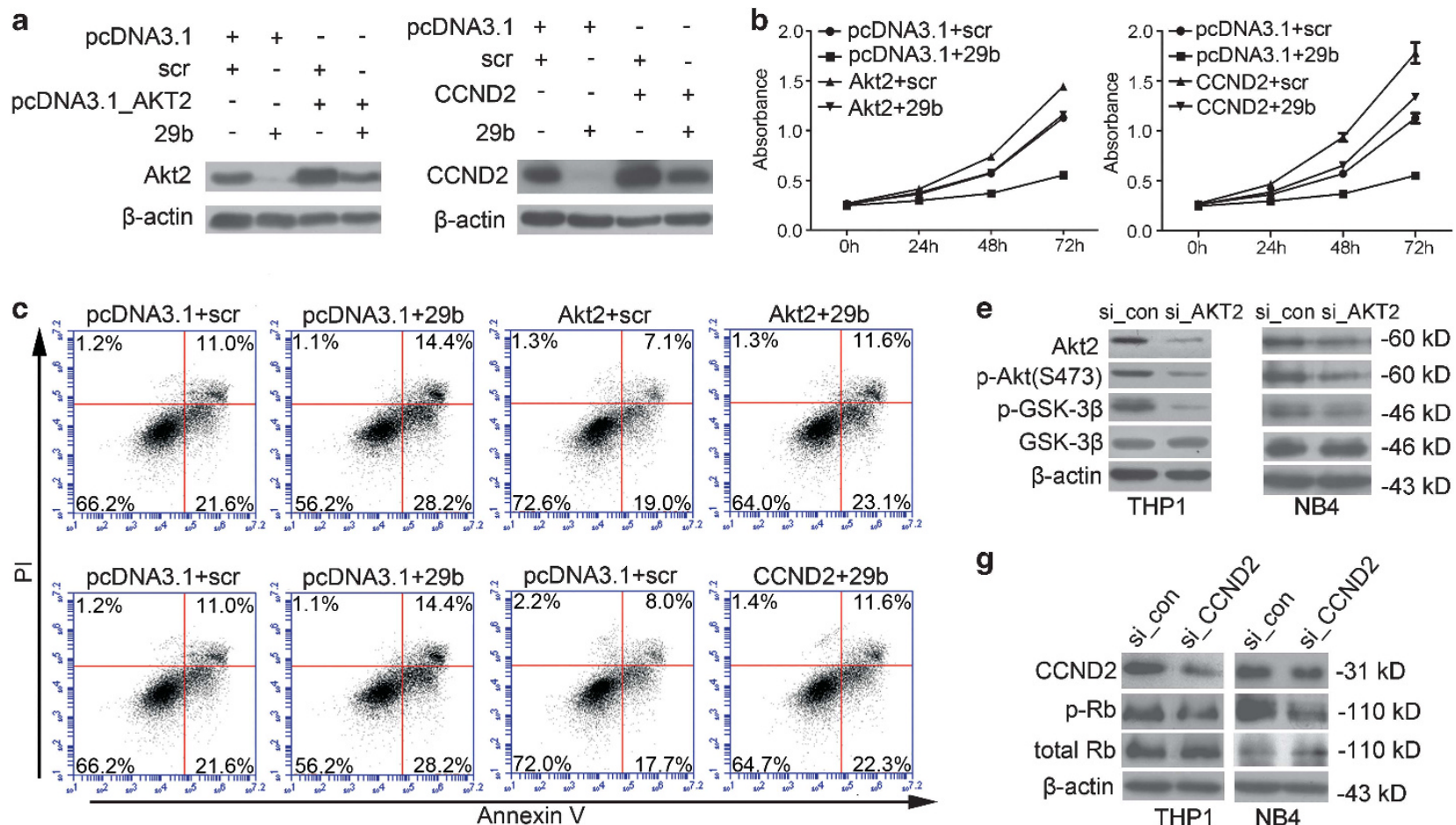

g

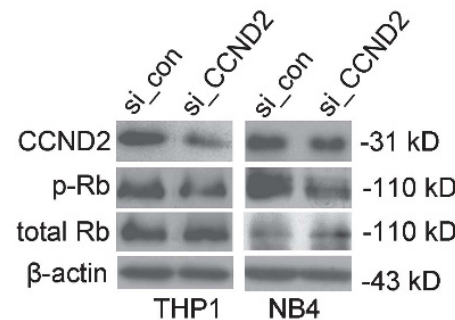

d
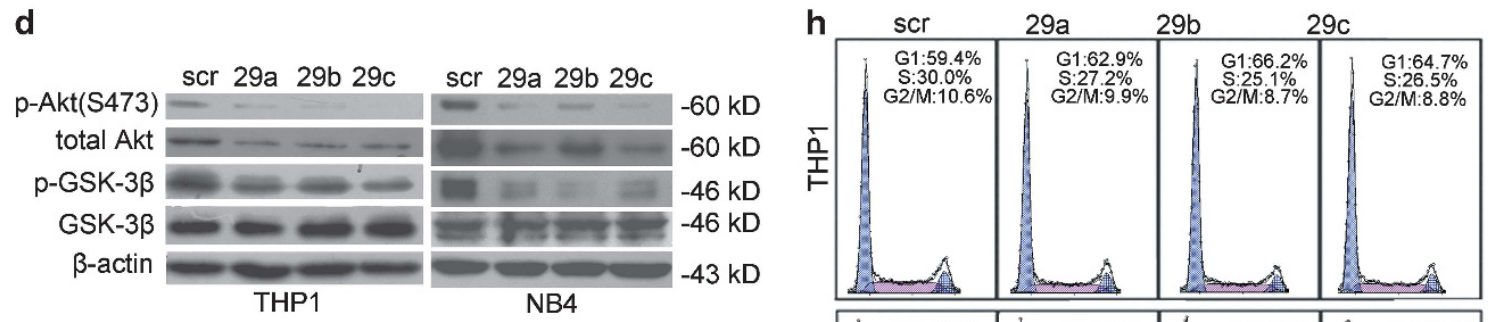

f
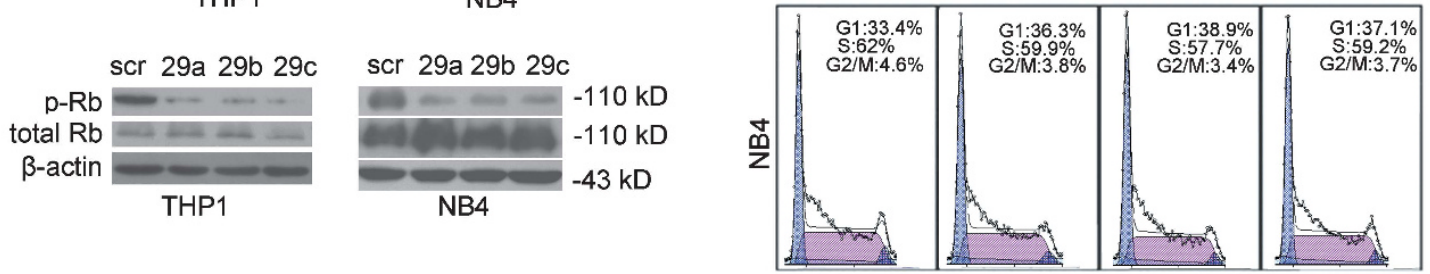

Figure 3 MiR-29s function through targeting AKT2 and CCND2 directly and rely on the downstream p-Akt and p-Rb pathways. (a) Immunoblotting of Akt2 and CCND2 in NB4 cells that were transfected with mimic control (scr) or miR-29b mimic for $24 \mathrm{~h}$ and then subsequently treated for another $48 \mathrm{~h}$ with pcDNA3.1 empty vector or pcDNA3.1_Akt2 (or pcDNA3.1_CCND2). (b and $\mathbf{c}$ ) Cell growth curves and Annexin V/PI assays in NB4 cells transfected with different combinations. (d and e) Detection of p-Akt (S473) and the p-GSK-3 $\beta$ (Ser9) levels in NB4 and THP1 after transfection with miR-29a, -29b or -29c mimics/mimic control (d) and si_con/si_AKT2 (e) for $48 \mathrm{~h}$. ( $f$ and $\mathbf{g}$ ) Detection of $\mathrm{p}-\mathrm{Rb}$ level in NB4 and THP1 after transfection with miR-29a, b or c mimics/mimic control (f) and si_con/si_CCND2 (g) for $48 \mathrm{~h}$. (h) Cell cycle distribution of THP1 and NB4 after transfection with miR-29s for $48 \mathrm{~h}$ 
The above data confirmed that the effects of miR-29s on cell proliferation and apoptosis were attributed to their target proteins, Akt2 and CCND2.

The regulation of miR-29 family on cell proliferation and apoptosis is dependent on the Akt pathway and p-Rb level. As Akt2 is one of three members of Akt family that functions as the hub in the PI3K/Akt signal pathway, ${ }^{37-39}$ we measured the levels of downstream p-Akt (Ser473) and p-GSK3 $\beta$ in NB4 and THP-1 cells after transfection with miR-29a, $-29 b,-29 c$ or control mimic for $48 \mathrm{~h}$ and found that overexpression of each miR-29 family member downregulated the phosphorylation levels of Akt and GSK3 $\beta$ (Figure $3 d$ ), which was consistent with the observation that transfection of NB4 and THP-1 cells with the siRNAs that specifically probed to AKT2 decreased p-Akt and p-GSK3 $\beta$ levels (Figure $3 e$ ).

CCND2 is one member of the cyclins participating in promoting the transition of cell cycle from $\mathrm{G} 1$ phase to $\mathrm{S}$ phase and functions through regulating phosphorylation of $\mathrm{Rb}$. $^{40,41}$ Therefore, we measured $\mathrm{p}-\mathrm{Rb}$ and total Rb in NB4 and THP1 cells and observed a decreased $\mathrm{p}-\mathrm{Rb}$ level after transfection with each miR-29 member, whereas the level of total $\mathrm{Rb}$ unchanged (Figure $3 \mathrm{f}$ ). Knockdown of the endogenous CCND2 could 'phonoscope' the function of miR-29 on $\mathrm{Rb}$ phosphorylation in both NB4 and THP-1 (Figure 3g). We next detected the DNA context using flow cytometry in miR-29 mimics- and CCND2 siRNAs-treated NB4 and THP-1 cells and observed that both miR-29 mimics (Figure $3 \mathrm{~h}$ ) and CCND2 siRNAs (Supplementary Figure S5) inhibited the G1 to $S$ transition in these cells. These data demonstrated that miR-29s could inhibit cell proliferation and induce cell apoptosis through regulating the Akt pathway and the $p-R b$ level.

\section{MiR-29a/b/c expression was negatively correlated with Akt2 and CCND2 expression in the PBMNC samples. To further elucidate the relationship between miR-29 family and Akt2/CCND2 expression in primary samples, we firstly detected Akt2 and CCND2 in PBMNC samples derived from 20 newly diagnosed $A M L$ patients and 23 healthy controls and a significantly increased Akt2 and CCND2 protein expression was observed in AML patients (Figures $4 a, b$ and Supplementary Figure S6). However, a significantly downregulated miR-29a, $-29 b$ and $-29 c$ expression levels were detected in the same AML samples (Figure 4c). The scatter plot and the Pearson correlation analysis further showed that $\mathrm{miR}-29 \mathrm{a} / \mathrm{b} / \mathrm{c}$ expression was negatively corre- lated with the target protein levels in the PBMNC samples (Figures $4 d, e$ ). These data suggested that the decreased miR-29s expression is related to the increased Akt2 and CCND2 levels in most of the AML patients.}

A feed-back loop comprising of c-Myc, miR-29 family and Akt2 is involved in myeloid leukemogenesis. It had been reported that $\mathrm{c}-\mathrm{Myc}$ negatively regulated the expression of miR-29a $\sim 29 b-1$ and miR-29b-2 29 c clusters at the transcriptional level. ${ }^{42-44}$ We thus deduced that the decreased miR-29 family levels in AML cases might arise from deregulated c-Myc expression. As expected, the levels of mature miR-29a, $-29 b$ and $-29 c$ were increased after knockingdown the endogenous c-Myc expression in THP1 cells (Figure 5a). Correspondingly, the protein levels of Akt2 and CCND2 were decreased (Figure 5b). Conversely, overexpression of c-Myc inhibited miR-29 family expression, (Figure 5c) which resulted in increased Akt2 and CCND2 protein expression (Figure $5 d$ ). These results proved that c-Myc-induced miR-29 downregulation led to the increase of both target proteins. Interestingly, c-Myc had been reported to be one of the downstream effectors of the PI3K/AKT pathway. To test whether Akt2 could affect miR-29 expression through regulating c-Myc, we transfected THP-1 and NB4 cells with AKT2-specific siRNA and found that the knockdown of $A K T 2$ resulted in a reduced c-Myc expression, which in return resulted in an increase of miR-29s expression (Figures $5 \mathrm{e}$ and $\mathrm{f}$ ). Inversely, overexpression of Akt2 upregulated c-Myc expression (Figure $5 \mathrm{~g}$ ), which further repressed miR-29 family expression in THP-1 cells (Figure 5h). Then we detected the expression of c-Myc in the AML patients who had been demonstrated having a significantly high Akt2 expression (see Figure 4), and observed that c-Myc protein was also upregulated in these AML cases (Figure $5 i$ and Supplementary Figure S7). These results suggested that a feed-back loop comprising of c-Myc, miR-29 family and Akt2 is involved in myeloid leukemogenesis.

Reintroduction of each miR-29 member can partially correct abnormal cell proliferation and apoptosis repression and myeloid differentiation arrest in AML BM blast cells. To examine the function of miR-29 members in AML blasts, we first analyzed the expression of miR-29s in BM CD34 + cells derived from five healthy donors and 20 primarily diagnosed AML patients and detected significantly decreased expression of all of the three miRNAs in AML BM CD34 + cells (Figure 6a and Supplementary Table 1). Then BM CD34 + cells derived from three AML patients (no. 6, M4; no. 1, M2 and no. 11, M5) were infected with the recombinant viruses expressing miR-29a, -29b, -29c and GFP, respectively. The infection efficiency was confirmed by real-time PCR, and the GFP-positive cells were collected for analysis. The proliferative activity of cells was detected at day 3, 5, 7 and 9, and the percentages of cells at early and late apoptosis stages were measured at day 5 after infection. The results showed that overexpression of each miR-29 member inhibited cell proliferation (Figure $6 \mathrm{~b}$ ) and induced cell apoptosis (Figure 6c) in the AML blasts. Moreover, reintroduction of each miR-29 member suppressed Akt2 and CCND2 expression in the AML blasts (Figure 6d), which further confirmed that the miR-29 members participated in regulating cell proliferation and cell apoptosis at least partially through repressing Akt2 and CCND2 expression.

As our previous work showed positive regulation of miR-29a on granulocytic and monocytic differentiation and reintroduction of miR-29a into AML BM CD34 + cells could overcome the differentiation arrest, we examined whether miR-29b and miR-29c have the same effects as miR-29a. Following virus infection of BM CD34 + cells derived from no.6, no.1 and no.11, the cells were induced to monocytic and granulocytic differentiation simultaneously or individually. By flow 
a

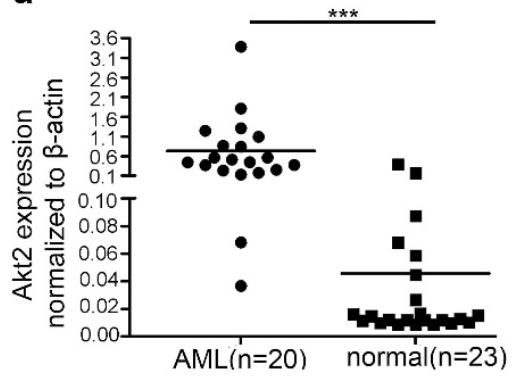

d

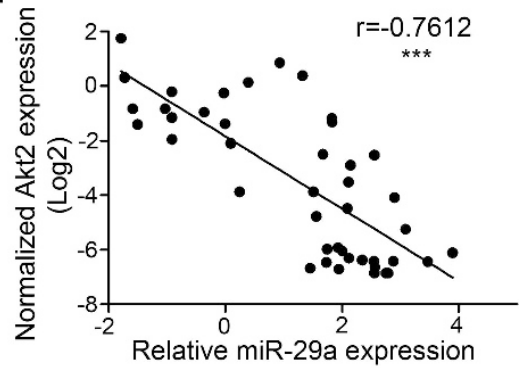

(Log2)

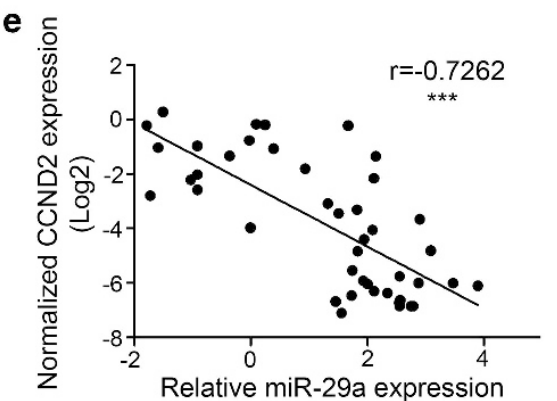

(Log2) b
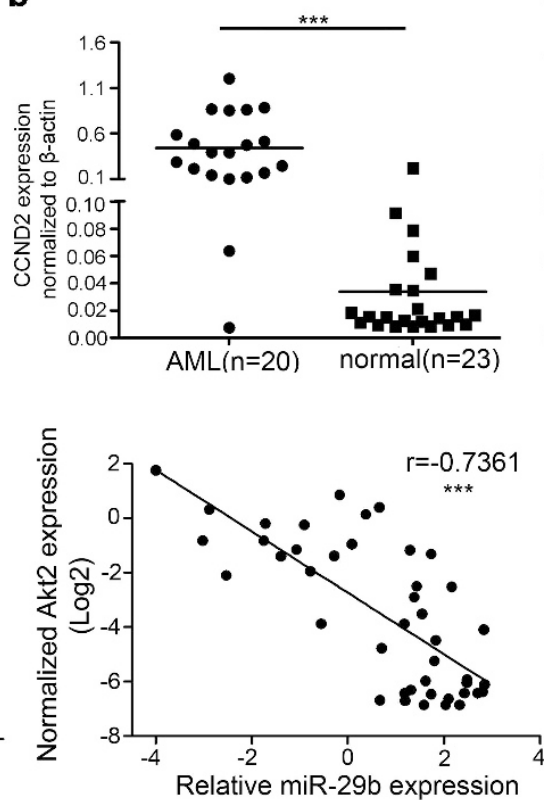

(Log2)

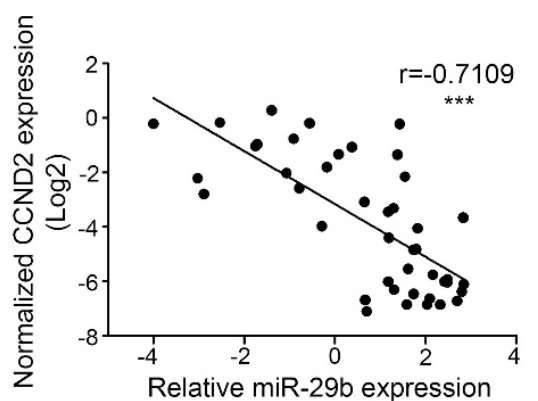

(Log2)
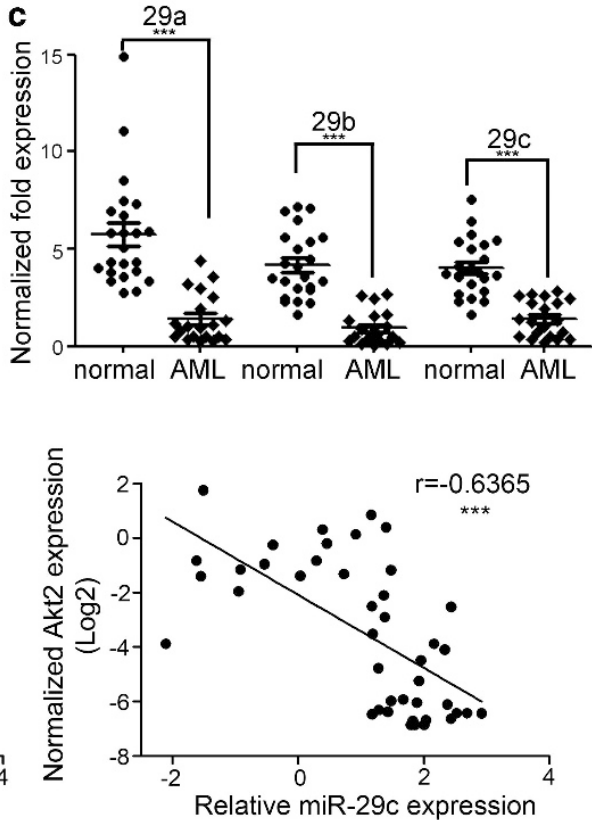

(Log2)

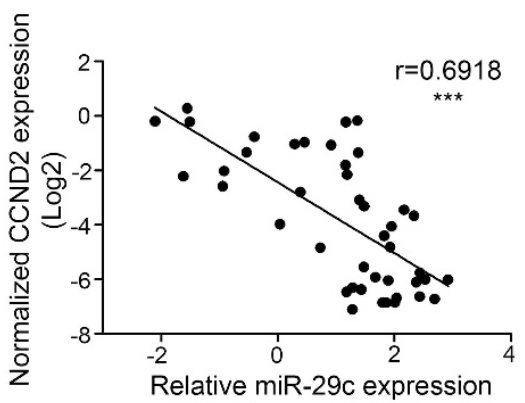

(Log2)

Figure 4 MiR-29a/b/c expression was negatively correlated with the protein levels of target genes, AKT2 and CCND2, in the PBMNC samples. (a and b) Western blotting analysis of Akt2 and CCND2 expression in the PBMNC samples derived from 23 healthy donors and 20 AML patients. Quantification of the expression levels of Akt2 and CCND2 was performed by using the Image $\mathrm{J}$ software and normalized to $\beta$-actin. ${ }^{* \star *} P<0.0001$. (c) Taqmam stem-loop RT-RCR analysis of miR-29a, $-29 \mathrm{~b}$ and $-29 \mathrm{c}$ expression in the PBMNC samples. ${ }^{* \star *} P<0.0001$. (d and e) Pearson correlation analysis between miR-29a/b/c and Akt2/CCND2 expression in the PBMNC samples. The Pearson correlation coefficient $r$ was calculated and verified by the two-tailed significance test. ${ }^{* \star *} P<0.0001$

cytometry of the myeloid differentiation markers (CD11b and CD14) and May-Grünwald Giemsa staining, we observed that, consistent with miR-29a, reintroduction of miR-29b or $-29 c$ in $\mathrm{AML}$ CD34 + cells significantly promoted granulocytic and monocytic differentiation (Supplementary Figures S8-S10).

Intravenous injection of miR-29s inhibits leukemic spreading in the AML model mice. For further examining the potential of miR-29 family in AML therapy, we constructed the AML murine model by tail vein injection of HL-60 cells in NOD/SCID mice (Figure 7a). At about 30 days after injection, the mice showed marked leukemic symptoms including paresis in the rear limbs, ruffled fur, remarkably hunched posture and splenomegaly. Then $1 \times 10^{7}$ IFU viral particles that express miR-29a, -29b, -29c and GFP, respectively, were injected intravenously into the $A M L$ mice. Fifteen days later, the mice treated with the viruses expressing any miR-29 member showed a significant reduction of leukemic cells in the BM and spleen as compared with those injected with the virus expressing the empty virus vector (Figures $7 \mathrm{~b}$ and $\mathrm{c}$ ). Importantly, local necrosis was found in the control mice, whereas splenomegaly was relieved obviously in the mice treated with the virus expressing miR-29a, -29b or -29c (Figure 7d). Haematoxylin and eosin (H\&E) staining of spleens collected from the control mice showed serious neoplastic infiltration by HL-60. However, the spleens from the mice treated with each miR-29 member had reduced neoplastic infiltration (Figure 8a, upper and Supplementary Figure S11). Besides, immunohistochemistrical analysis of the proliferative marker $\mathrm{Ki}-67$ and the apoptopic marker caspase-3 was performed in the spleen sections and the results showed decreased cell proliferative rate and higher caspase-3 level in the mice treated with each miR-29 member (Figure 8a, middle and lower; Supplementary Figures S12 and S13). Furthermore, significantly decreased protein levels of Akt2 and CCND2 

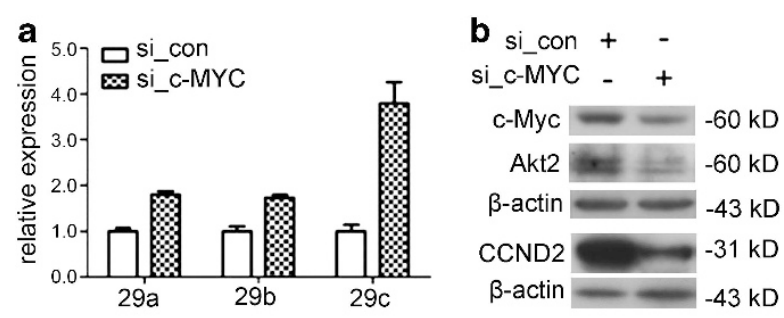
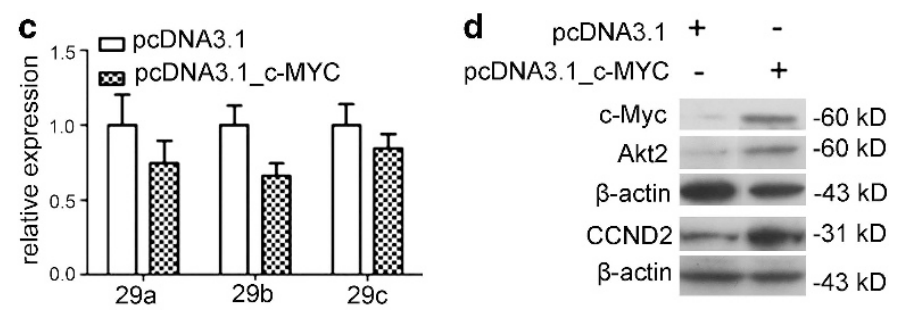

NB4
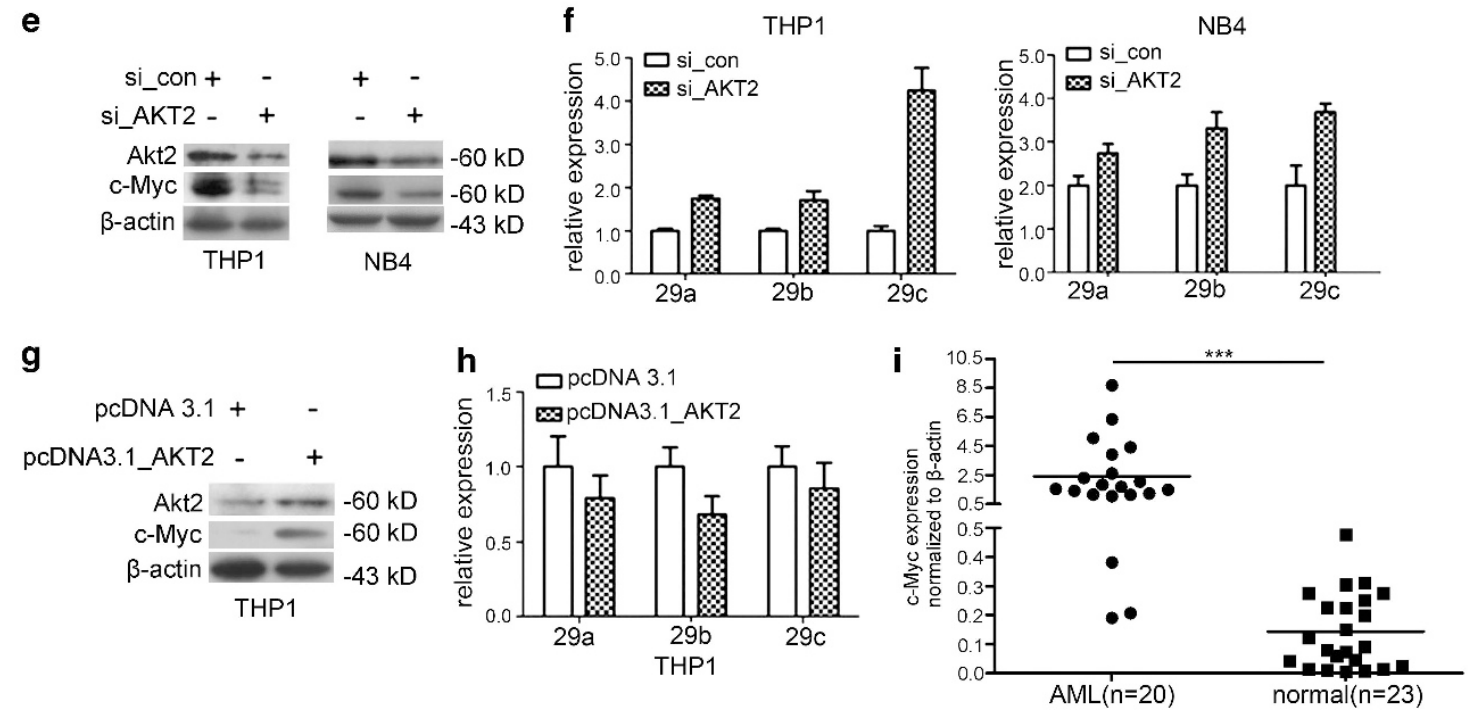

Figure 5 A feed-back loop comprising c-Myc, miR-29 family, Akt2 is involved in myeloid leukemogenesis. (a and $\mathbf{b})$ c-MYC knockdown enhanced miR-29s expression, leading to the downregulation of Akt2 and CCND2 in THP1 cells. (c and d) c-MYC overexpression repressed miR-29s expression, leading to the upregulation of Akt2 and CCND2, in THP1 cells. (e and f) AKT2 knockdown resulted in a downregulation c-Myc expression, leading to elevated expression of miR-29 family, in both THP-1 and NB4 cells. (g and $\mathbf{h}$ ) AKT2 overexpression elevated c-Myc expression, leading to a decreased miR-29 family expression, in THP1 cells. (i) c-Myc protein levels in PBMNCs used in figure 4. The western blot gels were shown in Supplementary Figure S4. ${ }^{* *} P<0.0001$

were detected in the $\mathrm{BM}$ and spleens of miR-29 membertreated mice (Figure $8 \mathrm{~b}$ ). These results indicated that miR-29a, $-29 b$ and $-29 c$ have great potential in AML therapy and they affected $A M L$ development at least partially through targeting oncogenes: AKT2 and CCND2.

\section{Discussion}

The vital role of miR-29 family members as tumor suppressors or oncogenes has been studied by several groups. To the best of our knowledge, this is the first study to explore their therapeutic roles in the AML model mice. We first confirmed that all of the miR-29 members were coincidently downregulated in PBMNCs and BM CD34 + cells derived from AML patients (M1-M5 subtypes) and found that the deregulated miR-29 family expression could be as markers for AML diagnosis. Reintroduction of miR-29a, -29b and -29c individually significantly inhibited proliferation, induced apoptosis and promoted the myeloid differentiation of HSPCs from AML patients and AML cell lines. Finally, we proved that ectopic administration of each miR-29 member relieved leukemic symptoms significantly in the AML model mice.

The role of miR-29a and miR-29b as the tumor suppressor has been reported in AML. Our previous work demonstrated that miR-29a is involved in the regulation of normal myeloid differentiation via negative regulation on cyclin T2 (CCNT2) and cyclin-dependent kinase 6 (CDK6) genes, and enforced the expression of miR-29a in CD34 + HSPCs derived from health controls and $\mathrm{AML}$ patients could promote myeloid differentiation. ${ }^{34}$ Another group also reported that overexpression of miR-29a and miR-29b reduced cell growth and induced cell apoptosis in K562 and Kasumi cells, and reduced tumorigenicity in the xenograft leukemia model mice through targeting CDK6, MCL 1 and CXXC6. ${ }^{28}$ Contrary to the above results, one group reported that overexpression of miR-29a in the hematopoietic system resulted in biased myeloid lineage development and development of a myeloproliferative disorder that progresses to AML. Besides, the overexpression of miR-29a enhanced proliferation at the level of multipotent progenitors and in 293T but not in common myeloid progenitors or granulocyte-macrophage progenitors. ${ }^{36}$ We speculated that the paradoxical results might result from the differences in differentiation stages and cell types.

The underlying mechanisms of miR-29 members to regulate cell proliferation, differentiation and apoptosis have been illustrated in different cell types. The miR-29 miRNAs could repress two p53 inhibitors, p85 and CDC42, to restore p53 expression in HCC cells. ${ }^{45}$ So far, several antiapoptotic genes were also identified as targets of the miR-29 members. For example, it has been suggested that the loss of the regulation of $\mathrm{Tcl}-1$ by $\mathrm{miR}-29$ facilitates the upregulation of $\mathrm{Tcl}-1$ in aggressive B-chronic lymphocytic leukemia. ${ }^{46}$ 
a

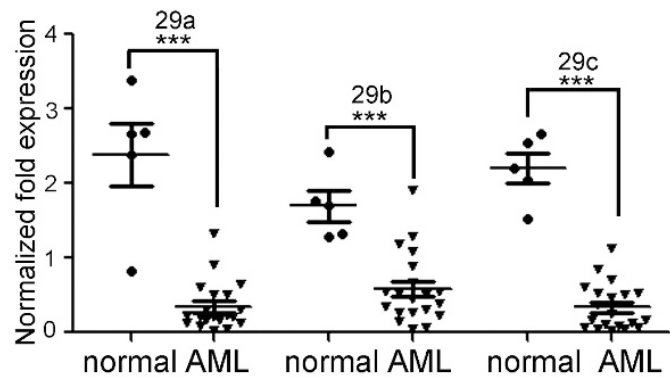

b

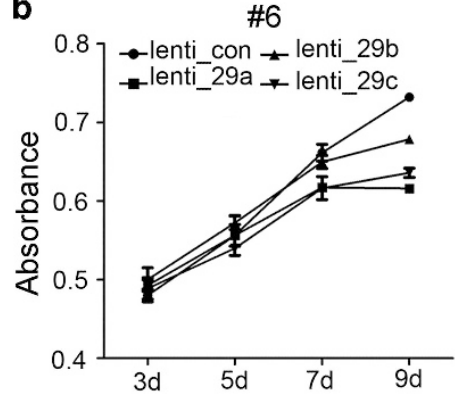

\#1

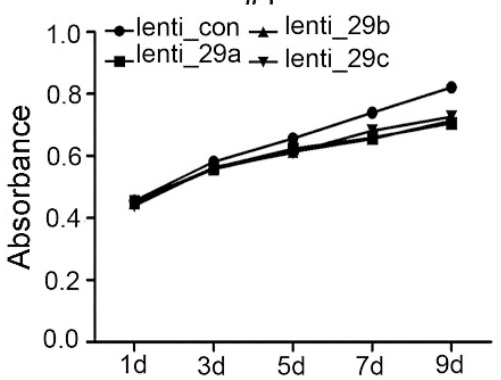

\#11

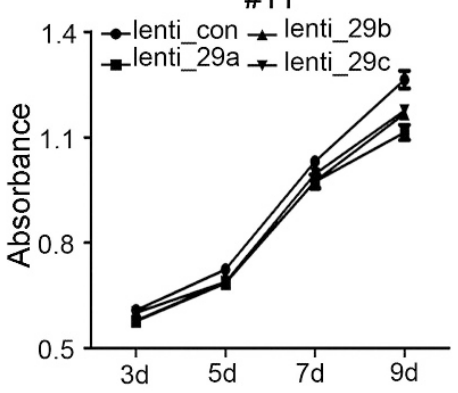

c

里

Ienti_con $\frac{2}{2}$ lenti_29a

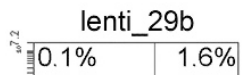
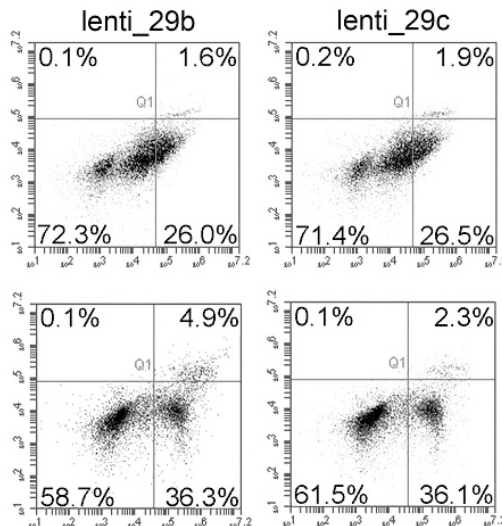

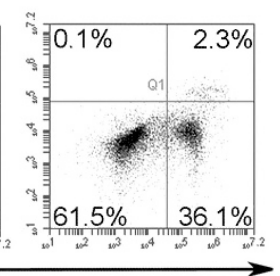

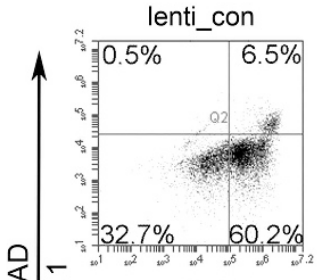

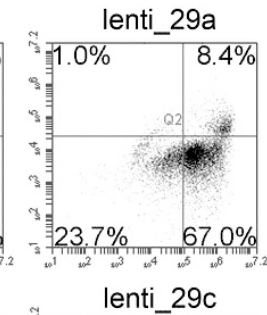

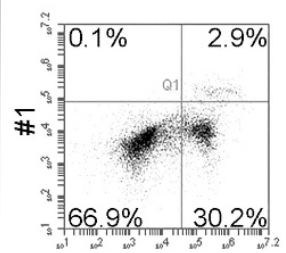

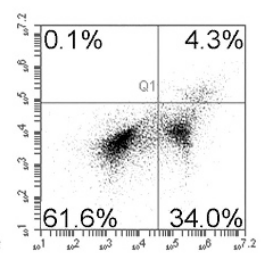

这
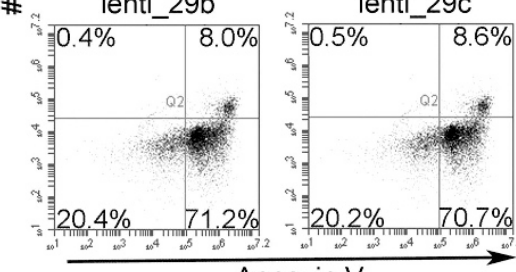

d
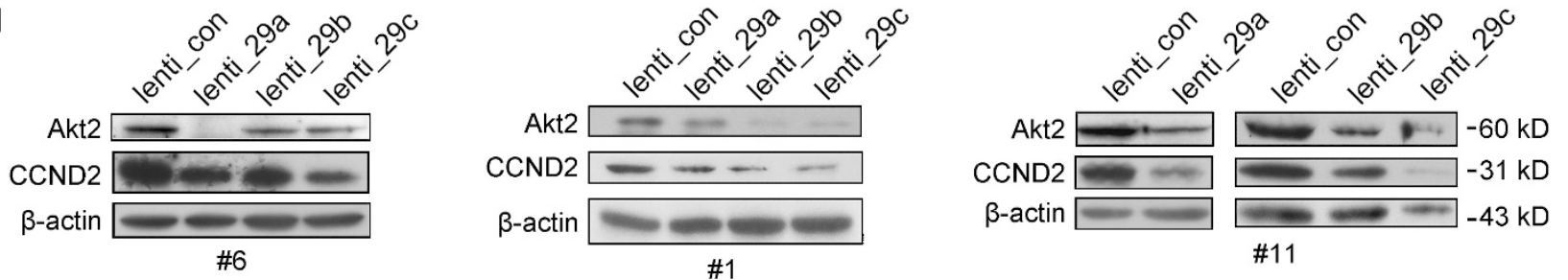

Figure 6 Ectopic expression of miR-29s can partially correct abnormal cell proliferation and apoptosis inhibition in AML BM CD $34+$ cells through targeting AKT2 and CCND2. (a) The relative expression of miR-29a, $-29 b$, and $-29 c$ in BM CD34 + cells from five healthy donors and 20 primarily diagnosed AML patients were detected by Taqman stem-loop RT-PCR. U6 snRNA was used as the internal control. The PCR of each sample was performed in triplicate. The same sample was detected in each realtime PCR operation to eliminate the errors among different plates. ${ }^{* \star *} P<0.0001$. (b) Cell growth curves of BM CD34 + cells derived from three AML patients after infection with lenti_29a, lenti_29b, lenti_29c and lenti_con, respectively. (c) Annexin V/7-AAD assays of the BM CD $34+$ cells after infection with the viruses for 4 days. (d) Western blotting analysis of Akt2 and CCND2 in the BM CD34 + cells after infection for 5 days

The Tcl-1 proto-oncoprotein, as an important coactivator of Akt, mediates the antiapoptotic signaling in various tumor cells. ${ }^{46}$ Recent work showed that miR-29 members could participate in the YAP-PI3K-PTEN-mTOR signaling pathway through targeting PTEN to regulate organ development. ${ }^{47}$ Moreover, MiR-29 could also promote tumor migration through targeting
PTEN in breast cancer cells and hepatoma cells. ${ }^{32,33}$ The phosphatidylinositol 3' kinase (PI3K) pathway is one of the most potent pro-survival pathways in cancers. It had been reported that primary cells from AML patients had constitutive the activation of the PI3 kinase mediator Akt. Inhibition of PI3 kinase in a short-term culture system led to decreased growth 


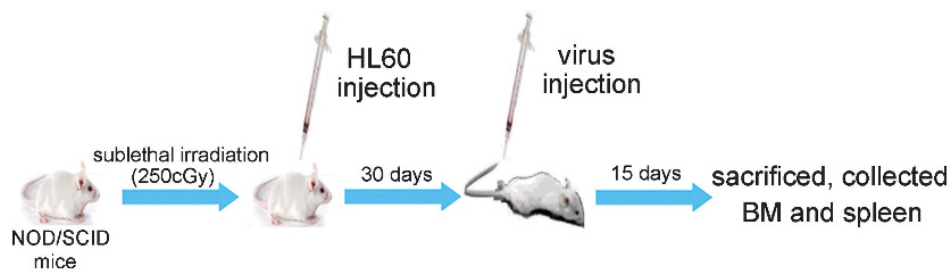

d untreated con $29 a \quad 29 b \quad 29 c$
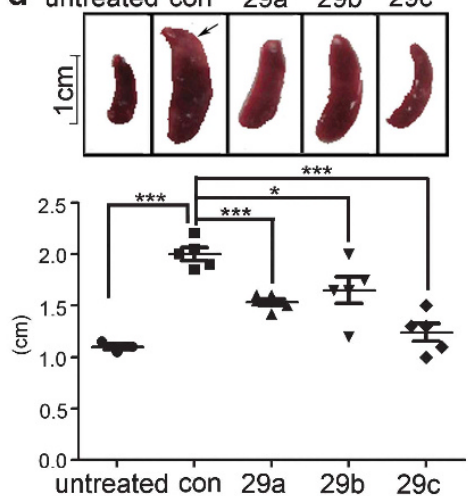

b
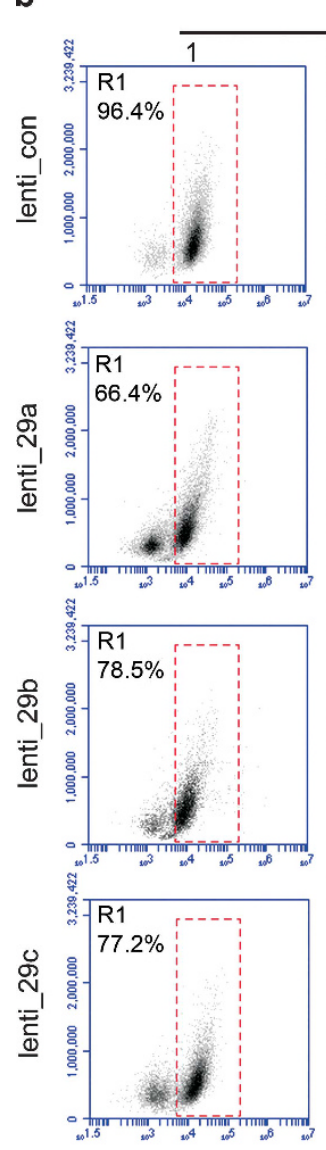

BM
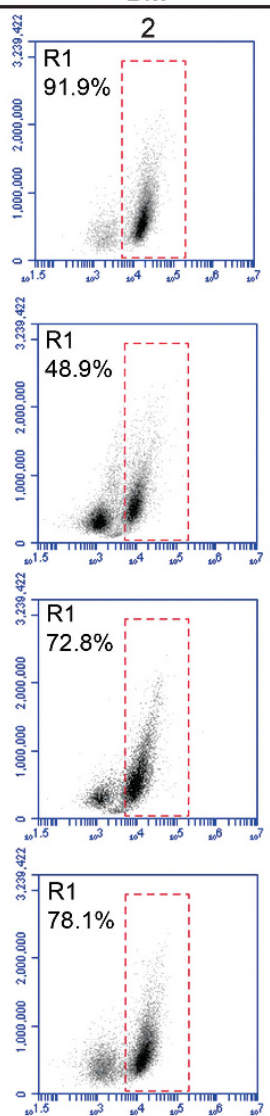
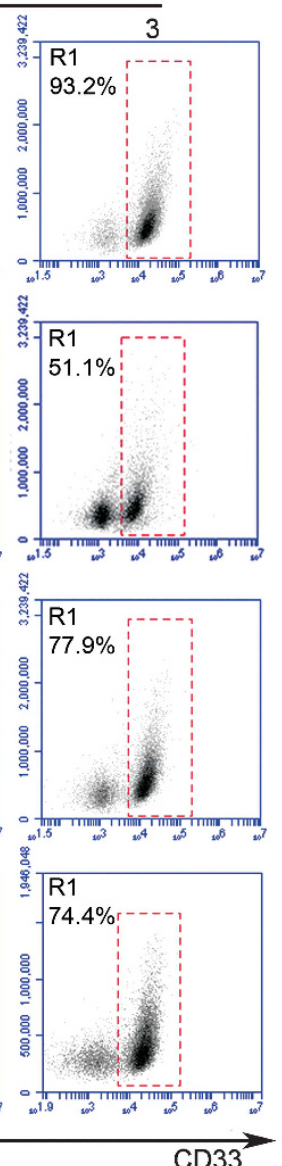

c
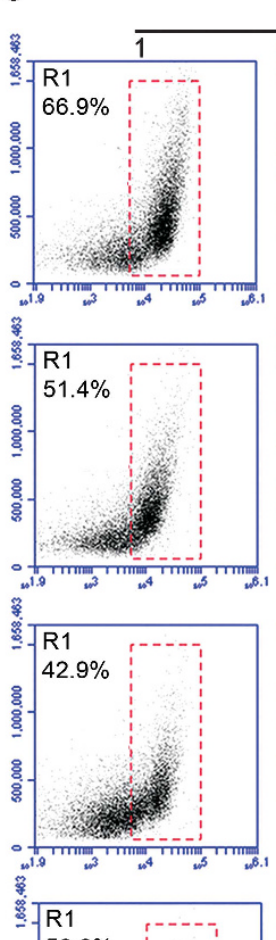

.1.
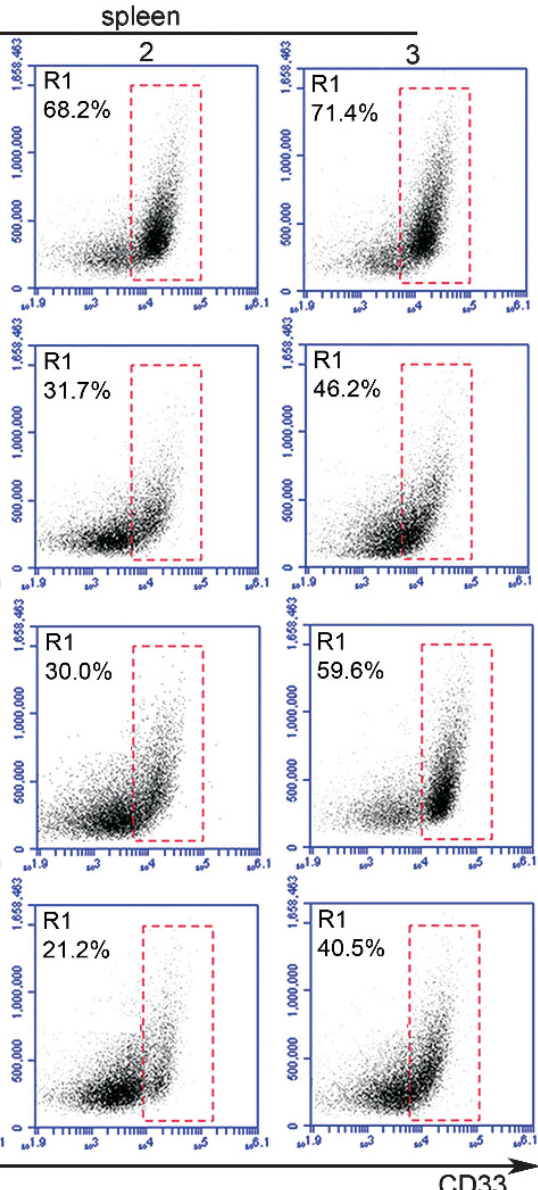

Figure 7 Intravenous injection of miR-29s inhibits leukemic spreading in AML model mice. (a) Diagram illustrating the experimental design in NOD/SCID mice. (b and c) Percentage of human CD33 + cells engrafted in the murine BM and spleen was determined by FACS. The results of three mice from each group were shown. (d) Measurement of spleen size in mice. Representative of the spleen of one mouse obtained from each group (upper). Statistic analysis of spleen size among different group (lower): untreated $(n=3)$, con $(n=5), 29 \mathrm{a}(n=5), 29 \mathrm{~b}(n=5), 29 \mathrm{c}(n=5)$. Untreated and con: ${ }^{* * *} P<0.0001$; con and 29a: ${ }^{* * *} P<0.001$; con and 29b: ${ }^{*} P<0.05$; con and 29c: ${ }^{* \star *} P<0.0001$

in most $A M L$ samples and was associated with the apoptopic induction in these cells. ${ }^{48}$ However, in human CD34 + cells, only low levels of Akt activation were shown. ${ }^{48}$ Akt2 is a homolog of the v-akt oncoprotein, a serine/threonine kinase pro-survival protein, which is activated by the PI3K pathway. In the present work, we demonstrated that AKT2 mRNA as a common target of miR-29a, -29b and -29c, and knockdown of
AKT2 could 'phenocopied' miR-29s' functions and inhibitory effects on p-Akt (S473) activity in AML cell lines. Rescue experiment further confirmed that the miR-29 family members functioned through downregulating Akt2 expression directly to promote cell apoptosis and reduce cell proliferation.

Several cell cycle-related proteins, including $\mathrm{CDK}^{28}$ and CCNT2, ${ }^{34}$ have been confirmed to be target proteins of the 
a
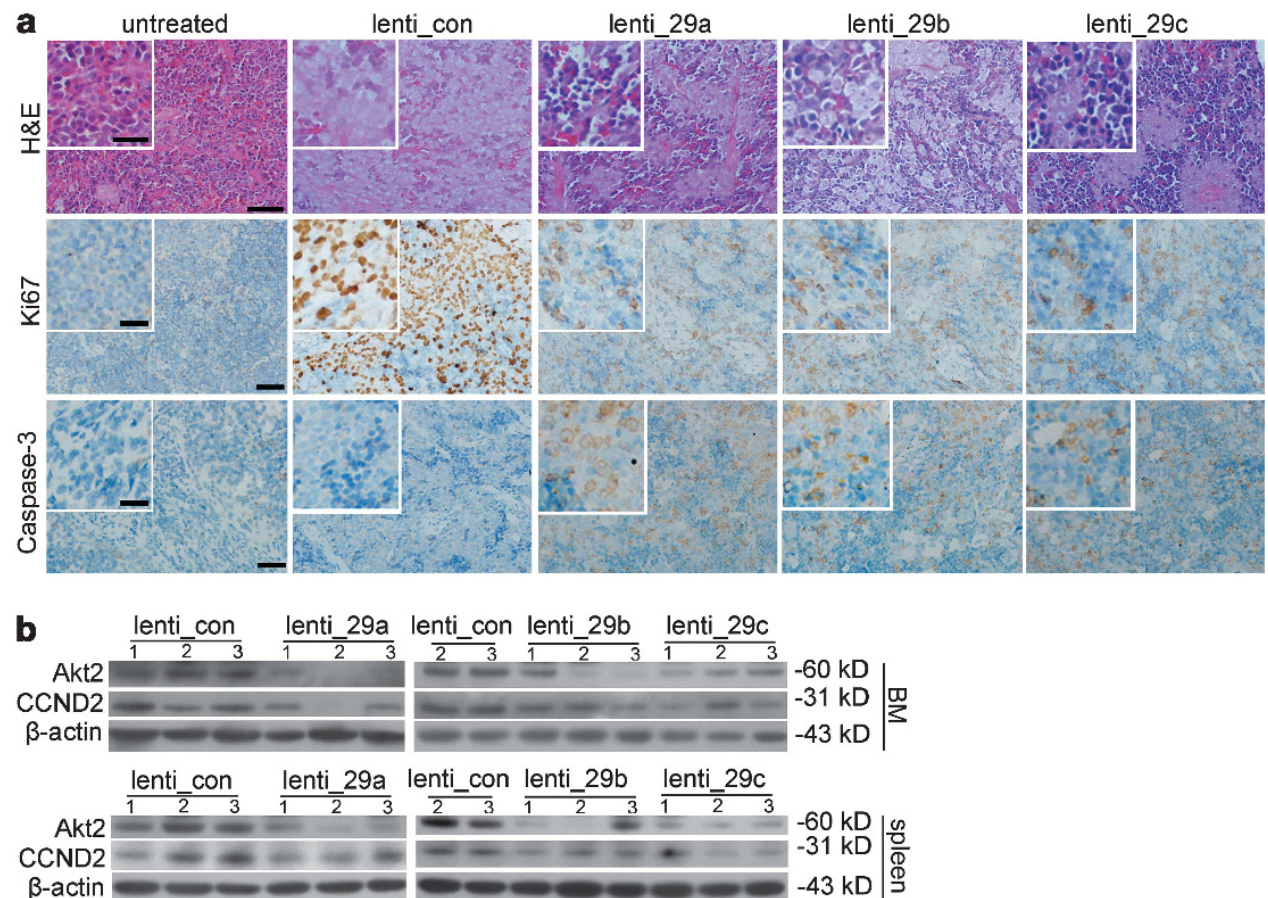

Figure 8 Histological and immunohistochemical analysis of spleens collected from the experimental NOD/SCID mice and western blot assays of the target proteins. (a) Spleen sections obtained from NOD/SCID mice with different treatments were analyzed for the degree of engraftment by H\&E (upper), Scare bar: $50 \mu \mathrm{m}$ (inset: $20 \mu \mathrm{m}$ ); cell proliferation by Ki-67 staining (middle) and apoptosis by caspase-3 staining (lower), Scare bar: $20 \mu \mathrm{m}$ (inset: $10 \mu \mathrm{m}$ ). The results of one mouse from each group were shown. (b) Western blotting analysis of Akt2 and CCND2 protein levels in murine BM and spleen. The results of three mice from each group were shown

miR-29 members and function in AML development. It has been reported that miR-29s target CCND2 in Rhabdomyosarcoma. ${ }^{49}$ Herein, we showed that the function of miR-29s to inhibit cell proliferation and induce cell apoptosis was also attributed to their repression on CCND2 protein expression and the responsive decrease of downstream $\mathrm{p}-\mathrm{Rb}$ level. Knockdown of CCND2 led to the arrest of cells in G1 phase, which further resulted in decreased cell growth and increased cell apoptosis. Furthermore, overexpression of CCND2 could rescue the effects resulted from upregulated miR-29 expression. More importantly, increased Akt2 and CCND2 expression was detected in PBMNCs derived from AML patients, which was negatively correlated with the decrease of miR-29 family expression.

C-Myc was reported to negatively regulate miR-29 expression. ${ }^{42-44}$ To explore whether downregulated miR-29 expression was attributed to deregulated c-MYC expression in AML, we detected c-Myc expression in AML patients and performed gain- and loss-of-function experiments and found a feed-back loop comprising of c-Myc, miR-29 family, Akt2 being involved in myeloid leukemogenesis.

Recently, miRNAs have gained considerable attention as therapeutic targets in various diseases. Several strategies have been developed to restore the function of the miRNAs that are downregulated in cancer cells. A recent study showed that systemic delivery of a miR-34a mimic, in complex with a neutral lipid emulsion, was able to decrease tumor burden in a murine model of non-small cell lung cancer. ${ }^{50}$ Adenovirusassociated vectors-mediated the restoration of miR-26a expression in a mouse model of hepatocellular carcinoma resulted in significant suppression of proliferation and induction of apoptosis, thereby inhibiting cancer progression. ${ }^{51,52}$ In many cases including leukemia, the downregulation of miR-29 family correlated with more aggressive forms and poor prognosis of cancers. These results promote us to investigate whether ectopic implantation of the miR-29 members could have a therapeutic effect on AML. We demonstrated that reintroduction of each miR-29 member could partially correct abnormal cell proliferation and apoptosis repression and myeloid differentiation arrest in AML BM blasts. We also found that AML mice treated with each miR-29 member showed a dramatic reduction of $A M L$ cell engraftment in the mice $B M$ and spleens, relieved splenomegaly, reduced neoplastic infiltration, decreased cell proliferative and increased cell apoptosis activities in spleens. Further studies are required to ascertain the optimal dose for injection and improve the delivery system to get less toxic and higher efficiency.

Taken together, our data confirmed one new mechanism that c-Myc-induced the downregulation of miR-29 miRNAs and the responsive upregulation of their target proteins Akt2 and CCND2, which participates in regulating cell proliferation and cell apoptosis, is involved in the AML development. The results from treatment of AML BM blasts and the leukemic model mice with the miR-29 members suggested that restoration of miR-29 family expression in AML patients could provide a new strategy for AML therapy.

\section{Materials and Methods}

Cell lines and their maintenance. The human promyelocytic cell line NB4 and human acute monocytic leukemia cell line THP-1 as well as human embryonic kidney cell line 293T were maintained in RPMI-1640 medium (Gibco, BRL, UK) supplemented with 10\% FCS (Gibco), $50 \mathrm{U} / \mathrm{ml}$ penicillin, and $50 \mu \mathrm{g} / \mathrm{ml}$ 
streptomycin (Sigma, St. Louis, MO, USA) at $37^{\circ} \mathrm{C}$ in $5 \% \mathrm{CO}_{2}$. Lentivirus packaging cell line 293TN was cultured in DMEM medium (Gibco) supplemented with $10 \%$ FCS (Gibco).

Separation of mononuclear cells (MNCs) and CD34 + cells. The peripheral blood samples and BM samples from normal volunteers and AML patients were obtained from the Hematology Department of 303 Hospital in Nanning, and the Department of Hematology of the Affiliated Hospital of Inner Mongolia Medical College, China. These AML samples include the major FAB subtypes from M1 to M5 at specific differentiation states of granulocytic and monocytic lineages: 7 M1 samples, 24 M2 samples, 18 M3 samples, 12 M4 samples and $20 \mathrm{M} 5$ samples. The informed consents were obtained from all of the examined subjects and the related studies were approved by the ethics committees of the participating hospitals and institute. MNC fractions were isolated from the samples by percoll density gradient $(d=1.077)$ (Amersham Biotech, Little Chalfont, UK) and the BM MNC fractions were enriched for CD34 + HSPCs using magnetic-activated cell sorting technology according to the manufacturer's recommendations (Miltenyi Biotec Inc., Cologne, Germany). The PBMNCs and BM $\mathrm{CD} 34+$ cells were used for the preparation of RNA and proteins. The BM $\mathrm{CD} 34+$ cells were also used for further virus infection.

Recombination lentivirus construction and transduction. The self-inactivating transfer vector plasmids pMIRNA1, pSIH1-H1-siLuc-copGFPTM and the pPACKH1TM packaging kit were purchased from System Biosciences (SBI, Mountain View, CA, USA). A 500-bp DNA fragment including pre-miR-29a, a 500-bp DNA fragment including pre-miR-29b and a 1000-bp DNA fragment including pre-miR-29c were obtained by PCR amplification using the human genome DNA as the template and the primers as described in Supplementary Table 2. The fragments were inserted into the downstream of the CMV promoter in pMIRNA1 to get pMiR-miR-29a, pMiR-miR-29b and pMiR-miR-29c, respectively. The virus packaging was performed according to the manufacturer's instructions. The virus particles (lenti_miR-29a, -29b, -29c and lenti_control) were harvested and concentrated using PEG-it Virus Precipitation Solution (SBI). Virus titer was determined in 293TN cells using the global untrarapid lentiviral titer kit (SBI) and performed according to the manufacturer's instructions.

The isolated CD34 + cells were cultured in IMDM (Gibco) supplemented with $30 \% \mathrm{FCS}, 1 \% \mathrm{BSA}, 100 \mu \mathrm{M}$ 2-mercapto-ethonal, $100 \mathrm{ng} / \mathrm{ml}$ recombinant human SCF and $10 \mathrm{ng} / \mathrm{ml} \mathrm{IL-3,} 2 \mathrm{mM} \mathrm{L}$-glutamine, $60 \mathrm{mg} / \mathrm{ml}$ penicillin and $100 \mathrm{mg} / \mathrm{ml}$ streptomycin for 1 to 2 days before infection. After cell infection with the virus particles in the presence of polybrene (concentration) (Sigma-Aldrich, St. Louis, MO, USA), the medium was replaced by fresh induction medium. The induction mediums include the same contents as above, except $2 \mathrm{ng} / \mathrm{ml} \mathrm{IL-3,} 10 \mathrm{ng} / \mathrm{ml} \mathrm{IL-6}$ and $20 \mathrm{ng} / \mathrm{ml}$ G-SCF for granulopoietic differentiation; $2 \mathrm{ng} / \mathrm{ml} \mathrm{IL-} 3,1 \mathrm{ng} / \mathrm{ml} \mathrm{IL-6}$,

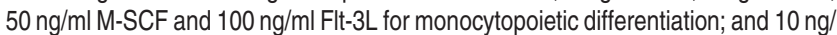
$\mathrm{ml} \mathrm{IL-3,} 10 \mathrm{ng} / \mathrm{ml}$ IL- $6,10 \mathrm{ng} / \mathrm{ml}$ GM-SCF and $100 \mathrm{ng} / \mathrm{ml} \mathrm{Flt-3} \mathrm{for} \mathrm{myeloid}$ (granulopoietic and monocytopoietic) differentiation. All the cytokines were purchased from PeproTech (PeproTech, London, UK).

Oligonucleotides, constructs and transfections. The mimics of MiR-29a, -29b and 29c, inhibitors and negative controls were purchased from Dharmacon (Chicago, IL, USA) and transfected into NB4 and THP1 using DharmaFECT 2 (Chicago, IL, USA) at a final concentration of $100 \mathrm{nM}$. The siRNAs probed to AKT2, CCND2, C-MYC as well as siRNA control were synthesized by Origene (Rockville, MD, USA) and transfected into NB4 and THP1 cells using DharmaFECT2 at a final concentration of $10 \mathrm{nM}$.

The open reading frames (ORFs), but not including the $3^{\prime}$ UTRs of AKT2, CCND2 and $c-M Y C$, were obtained by PCR amplification using human complementary DNA $(\mathrm{cDNA})$ as the template and inserted into pcDNA3.1 $(+)$. The PCR primers were described in supplementary Table 2 . The recombination expression plasmids were transfected into THP1 and NB4 cells using FuGENE HD transfection reagent (Roche, Penzberg, Germany) according to the protocol. The efficiency of transfection was confirmed by real-time PCR and western blot.

Dual luciferase reporter experiments. The 3' UTRs of AKT2 and CCND2 containing the predicted binding sites of miR-29a-, $-29 \mathrm{~b}$ - and $-29 \mathrm{c}$ were amplified by PCR from human cDNA using primers as described in Supplementary Table 2, and inserted into the pMIR-REPORT luciferase reporter vectors (Ambion, Austin, TX, USA) to get the constructs containing the wild-type AKT2 $3^{\prime}$ UTR and CCND2 3'UTR (AKT2_WT and CCND2_WT), respectively. AKT2_M-1 and
CCND2 M-1 contained the sequences with mutations in the first putative binding site of AKT2 3'UTR and CCND2 3'UTR, respectively. AKT2_M-2 and CCND2_M2 contained the sequences with mutations in the second putative binding site of AKT2 $3^{\prime}$ UTR and CCND2 $3^{\prime}$ UTR, respectively. The last two (AKT2_dM or CCND2_dM) contained the sequences with mutations in both binding sites of AKT2 $3^{\prime}$ UTR and CCND2 $3^{\prime} U T R$, respectively. Mutations of the predicted seed regions in these two mRNA sequences were created using the primers including the mutated sequences. The recombination constructs, pRL-TK (Promega, WI, USA) and miR-29a, $-29 b,-29 c$ or control mimic were co-transfected into 293T cells using lipofectamine 2000 (Invitrogen, Carlsbad, CA, USA). The plasmid of pRL-TK containing Renilla luciferase was used as internal control. Firefly and Renilla luciferase activity were measured using Dual Luciferase Assay (Promega) according to the manufacturer's instructions at $36 \mathrm{~h}$ after transfection. All transfection assays were carried out in triplicate.

RNA isolation, reverse transcription and quantitative RT-PCR. Total RNA was extracted from the harvested cells and tissues using Trizol reagent (Invitrogen) according to the manufacturer's instruction. cDNAs of mRNAs were obtained by using M-MLV reverse transcriptase (Invitrogen) and oligo(dT)18. For miRNAs, the stem-loop reverse transcription was manufactured according to the Chen's report. ${ }^{53}$ The primers for reverse transcription of miRNAs and quantitative RT-PCR as well as the taqman probes were described in Supplementary Table 2. Quantitative RT-PCR was carried out in the Bio-Rad IQ5 real-time PCR system according to the manufacturer's instruction (Bio-Rad, Hercules, CA, USA). The data were normalized using the endogenous $\beta$-actin and U6 snRNA for mRNA and miRNAs separately. The 2- $\Delta \Delta C T$ method was used in the analysis of PCR data.

Western blot analysis. Total protein extracts of cell lines and tissue samples were extracted using the radio immunoprecipitation assay (PIRA) buffer and stored at $-80^{\circ} \mathrm{C}$. Cell lysates ( $40 \mu \mathrm{g}$ of total protein extracts) and prestained molecular markers were subjected to electrophoresis on $12 \%$ polyacrylamide SDS gels. The antibodies include those against Akt2, p-Akt, Akt, GSK-3 $\beta$, p-GSK-3 $\beta$ (Ser9), CCND2, Rb, p-Rb (Ser780), c-Myc (Cell Signal Technology, Danvers, MA, USA) and $\beta$-actin. Immunoblots were quantified by Image $\mathrm{J}$ software (Free software utilised by $\mathrm{NIH}$ ).

Cell proliferation, apoptosis and cell cycle assays. Cells were reseeded into 96-well plates at a density of 10000 cells per well after transfection or infection for $12 \mathrm{~h}$. Cell viability was measured every $24 \mathrm{~h}$ by adding $10 \%$ CCK- 8 (DOJINDO, Japanese) and incubated at $37^{\circ} \mathrm{C}$ for $3 \mathrm{~h}$. The optical density was read at $450 \mathrm{~nm}$ with a microplate spectrophotometer. Each experiment was carried out in triplicate.

To examine whether miR-29a, $-29 \mathrm{~b}$ and $-29 \mathrm{c}$ induce apoptosis, AML cell lines were transfected with miR-29a, $b$ and $c$ mimics and negative control, respectively, and the apoptosis cells were detected using the FITC Annexin V Apoptosis detection kit 1 (BD, Franklin Lakes, NJ, USA) at $72 \mathrm{~h}$ after transfection. For the CD34 + cells derived from AML samples, the cells were infected with lenti_miR$29 \mathrm{a},-29 \mathrm{~b},-29 \mathrm{c}$ and lenti_control, respectively, and the apoptosis cells were detected using the PE Annexin V Apoptosis detection kit 1 at day 4 after infection.

For cell cycle analysis, at $48 \mathrm{~h}$ after transfection with miR-29a, $-29 \mathrm{~b},-29 \mathrm{c}$ or control mimic, the cells were harvested and washed twice with PBS and fixed in $75 \%$ ethanol overnight. The next day, cells were washed twice with PBS and incubated in RNaseA $(20 \mu \mathrm{g} / \mathrm{ml})$ at $37^{\circ} \mathrm{C}$ for $30 \mathrm{~min}$, then stained with propidium iodide $(\mathrm{PI}, 0.5 \mathrm{mg} / \mathrm{ml})$ at $4{ }^{\circ} \mathrm{C}$ for $30 \mathrm{~min}$. Finally, the cells were washed and resuspended in $500 \mu \mathrm{L}$ PBS followed by detecting the DNA content using Becton-Dickinson flow cytometer.

May-Grünwald Giemsa staining. The infected CD34 + cells derived AML samples were induced for monocytopoietic and granulopoietic differentiation and harvested every 3-5 days for staining. The harvested cells were washed twice with PBS and resuspended in serum, then the fresh prepared and air dried blood smears were fixed in methanol for $10 \mathrm{~min}$. The slides were stained in pure May-Grünwald solution for $5 \mathrm{~min}$, then washed in PBS for 5 min and incubated in a $10 \%$ Giemsa/water solution for $30 \mathrm{~min}$. The slides were then washed in PBS, air dried and observed under optical microscopy Olympus BX51 (Olympus, Tokyo, Japan).

Flow cytometric analysis. The infected AML CD34 + cells were induced for myeloid differentiation and harvested every 3-5 days for analysis. The 
harvested cells were washed twice and resuspended in $100 \mu$ l cold PBS, which were then incubated with PE-conjugated anti-CD11b and anti-CD14 (Biolegend, San Diego, CA, USA) on ice for $30 \mathrm{~min}$. Finally, cells were washed using cold PBS and fixed in $4 \%$ paraform for further analysis on Accuri $\mathrm{C} 6$ flow cytometer (BD).

In vivo studies. Five/six-week old female NOD/SCID mice were purchased and housed under specific pathogen-free conditions. All procedures involving animals were performed according to the institutional guidelines. HL-60 cells $\left(5 \times 10^{6}\right)$ suspended in $100 \mu$ l EDTA-PBS were injected into the tail vein of sublethally irradiated $(250 \mathrm{cGy})$ NOD/SCID mice. At about 30 days after injection, mice showed obvious leukemia signs. Then $1 \times 10^{7}$ IFU viral particles for miR-29a, -29b, -29c and negative control individually were injected into each mouse intravenously. Each group includes five mice. For mice in the 'untreated' group, $100 \mu \mathrm{l}$ EDTA-PBS were injected. At day 15 after injection, the mice were killed and the tissues including the spleen and BM obtained by femur flushing were collected for further detection. Single cell suspension from the spleen and BM was prepared for flow cytometric analysis and protein and RNA extractions. The red blood cell lysis buffer was used to exclude erythrocytes. The human specific CD33 surface maker was used to identify the human leukemia cells and the detailed procedure for flow cytometric analysis was same as the description above.

Histology and immunohistochemistry. Murine spleen tissue was fixed in $10 \%$ formalin for $24 \mathrm{~h}$, embedded in paraffin, cut into $4-\mu \mathrm{m}$-thick sections and stained with H\&E to perform the histological studies. Immunohistochemical staining was performed on formalin-fixed, paraffin-embedded murine spleen sections. Murine spleen sections were stained with the anti-human ki-67 (1:100 dilution, Abcam, Cambridge, UK) or anti-human caspase-3 (1:100 dilution, Abcam). To enhance immunostaining, the antigen was preretrieved in citrate buffer using pressure cooking within a calibrated microwave and heated for $1.5 \mathrm{~min}$. Slides were counterstained with Mayer's hematoxylin and photographed with optical microscopy Olympus BX51 (Olympus).

Statistics. Student's t-test (two-tailed) was performed to analyze the data. $P$-values $<0.05$ were considered significantly. The correlation between miR-29s expression and the protein levels of target genes was examined by the Pearson correlation analysis.

\section{Conflict of Interest}

The authors declare no conflict of interest.

Acknowledgements. This work was supported by the National Natura Science Foundation of China (30970616 and 31171311).

1. O'Donnell MR, Abboud CN, Altman J, Appelbaum FR, Arber DA, Attar E et al. Acute myeloid leukemia. J Natl Compr Canc Netw 2012; 10: 984-1021.

2. National cancer institute report on Acute myeloid leukemia. http://seer.cancer.gov/csr/ 1975_2009_pops09/. Based on November 2011 SEER data submission.

3. Bennett JM, Catovsky D, Daniel MT, Flandrin G, Galton DA, Gralnick HR et al. Proposals for the classification of the acute leukaemias. French-American-British (FAB) co-operative group. Br J Haematol 1976; 33: 451-458.

4. Atlas MP, Lipton JM. Treatment of relapsing AML following hematopoietic stem cell transplantation. Pediatr Transplant 2003; 7: 419-421.

5. Kimby E, Nygren P, Glimelius B. A systematic overview of chemotherapy effects in acute myeloid leukaemia. Acta Oncol 2001; 40: 231-252.

6. Juliusson G, Antunovic P, Derolf A, Lehmann S, Mollgard L, Stockelberg D et al. Age and acute myeloid leukemia: real world data on decision to treat and outcomes from the Swedish Acute Leukemia Registry. Blood 2009; 113: 4179-4187.

7. Krug U, Buchner T, Berdel WE, Muller-Tidow $C$. The treatment of elderly patients with acute myeloid leukemia. Dtsch Arztebl Int 2011; 108: 863-870.

8. Walter RB, Appelbaum FR, Estey EH, Bernstein ID. Acute myeloid leukemia stem cells and CD33-targeted immunotherapy. Blood 2012; 119: 6198-6208.

9. Bali $\mathrm{P}$, George $\mathrm{P}$, Cohen $\mathrm{P}$, Tao J, Guo F, Sigua $\mathrm{C}$ et al. Superior activity of the combination of histone deacetylase inhibitor LAQ824 and the FLT-3 kinase inhibitor PKC412 against human acute myelogenous leukemia cells with mutant FLT-3. Clin Cancer Res 2004; 10: 4991-4997.

10. George P, Bali P, Annavarapu S, Scuto A, Fiskus W, Guo F et al. Combination of the histone deacetylase inhibitor LBH589 and the hsp90 inhibitor 17-AAG is highly active against human CML-BC cells and AML cells with activating mutation of FLT-3. Blood 2005, 105: $1768-1776$.
11. Colado E, Alvarez-Fernandez S, Maiso P, Martin-Sanchez J, Vidriales MB, Garayoa M et al. The effect of the proteasome inhibitor bortezomib on acute myeloid leukemia cells and drug resistance associated with the CD34 + immature phenotype. Haematologica 2008; 93: $57-66$.

12. Trujillo $A$, McGee $C$, Cogle CR. Angiogenesis in acute myeloid leukemia and opportunities for novel therapies. J Oncol 2012; 128608.

13. Lin WH, Jiaang WT, Chen CW, Yen KJ, Hsieh SY, Yen SC et al. BPR1J-097, a novel FLT3 kinase inhibitor, exerts potent inhibitory activity against AML. Br J Cancer 2012; 106: 475-481.

14. Zhang W, Konopleva M, Shi YX, McQueen T, Harris D, Ling X et al. Mutant FLT3: a direct target of sorafenib in acute myelogenous leukemia. J Natl Cancer Inst 2008; 100: 184-198

15. Ambros V. microRNAs: tiny regulators with great potential. Cell 2001; 107: 823-826

16. He L, Hannon GJ. MicroRNAs: small RNAs with a big role in gene regulation. Nat Rev Genet 2004; 5: 522-531

17. Ke XS, Liu CM, Liu DP, Liang CC. MicroRNAs: key participants in gene regulatory networks. Curr Opin Chem Biol 2003; 7: 516-523.

18. Asangani IA, Rasheed SA, Nikolova DA, Leupold JH, Colburn NH, Post $\mathrm{S}$ et al. MicroRNA-21 (miR-21) post-transcriptionally downregulates tumor suppressor Pdcd4 and stimulates invasion, intravasation and metastasis in colorectal cancer. Oncogene 2008; 27: 2128-2136.

19. Jiang S, Zhang LF, Zhang HW, Hu S, Lu MH, Liang S et al. A novel miR-155/miR-143 cascade controls glycolysis by regulating hexokinase 2 in breast cancer cells. EMBO J 2012; 31: 1985-1998.

20. Takamizawa J, Konishi H, Yanagisawa K, Tomida S, Osada H, Endoh $\mathrm{H}$ et al. Reduced expression of the let-7 microRNAs in human lung cancers in association with shortened postoperative survival. Cancer Res 2004; 64: 3753-3756.

21. Li Y, Vecchiarelli-Federico LM, Li YJ, Egan SE, Spaner D, Hough MR et al. The miR-17-92 cluster expands multipotent hematopoietic progenitors whereas imbalanced expression of its individual oncogenic miRNAs promotes leukemia in mice. Blood 2012; 119: 4486-4498.

22. Li Z, Huang H, Li Y, Jiang X, Chen P, Arnovitz $S$ et al. Up-regulation of a HOXA-PBX3 homeobox-gene signature following down-regulation of miR-181 is associated with adverse prognosis in patients with cytogenetically abnormal AML. Blood 2012; 119: 2314-2324.

23. Pulikkan JA, Peramangalam PS, Dengler V, Ho PA, Preudhomme C, Meshinchi S et al. C/EBPalpha regulated microRNA-34a targets E2F3 during granulopoiesis and is down-regulated in AML with CEBPA mutations. Blood 2010; 116: 5638-5649.

24. Zhang $\mathrm{H}$, Luo $\mathrm{XQ}$, Feng DD, Zhang $\mathrm{XJ}$, Wu J, Zheng $Y S$ et al. Upregulation of microRNA$125 \mathrm{~b}$ contributes to leukemogenesis and increases drug resistance in pediatric acute promyelocytic leukemia. Mol Cancer 2011; 10: 108

25. Zhao JJ, Lin J, Lwin T, Yang $\mathrm{H}$, Guo J, Kong $\mathrm{W}$ et al. microRNA expression profile and identification of miR-29 as a prognostic marker and pathogenetic factor by targeting CDK6 in mantle cell lymphoma. Blood 2010; 115: 2630-2639.

26. Braconi C, Kogure T, Valeri N, Huang N, Nuovo G, Costinean S et al. microRNA-29 can regulate expression of the long non-coding RNA gene MEG3 in hepatocellular cancer. Oncogene 2011; 30: 4750-4756.

27. Xiong Y, Fang JH, Yun JP, Yang J, Zhang Y, Jia WH et al. Effects of microRNA-29 on apoptosis, tumorigenicity, and prognosis of hepatocellular carcinoma. Hepatology 2010; 51: $836-845$

28. Garzon R, Heaphy CE, Havelange V, Fabbri M, Volinia S, Tsao T et al. MicroRNA 29b functions in acute myeloid leukemia. Blood 2009; 114: 5331-5341.

29. Liu S, Wu LC, Pang J, Santhanam R, Schwind S, Wu YZ et al. Sp1/NFkappaB HDAC/miR-29b regulatory network in KIT-driven myeloid leukemia. Cancer Cell 2010; 17: 333-347.

30. Wang F, Wang XS, Yang GH, Zhai PF, Xiao Z, Xia LY et al. miR-29a and miR-142-3p downregulation and diagnostic implication in human acute myeloid leukemia. Mol Biol Rep 2012; 39: 2713-2722.

31. Fabbri M, Garzon R, Cimmino A, Liu Z, Zanesi N, Callegari E et al. MicroRNA-29 family reverts aberrant methylation in lung cancer by targeting DNA methyltransferases $3 \mathrm{~A}$ and 3B. Proc Natl Acad Sci 2007; 104: 15805-15810.

32. Kong G, Zhang J, Zhang S, Shan C, Ye L, Zhang X. Upregulated microRNA-29a by hepatitis $B$ virus $X$ protein enhances hepatoma cell migration by targeting PTEN in cell culture model. PLoS One 2011; 6: e19518.

33. Wang C, Bian Z, Wei D, Zhang JG. MiR-29b regulates migration of human breast cancer cells. Mol Cell Biochem 2011; 352: 197-207.

34. Wang XS, Gong JN, Yu J, Wang F, Zhang XH, Yin XL et al. MicroRNA-29a and microRNA142-3p are regulators of myeloid differentiation and acute myeloid leukemia. Blood 2012; 119: 4992-5004.

35. Nguyen T, Kuo C, Nicholl MB, Sim MS, Turner RR, Morton DL et al. Downregulation of microRNA-29c is associated with hypermethylation of tumor-related genes and disease outcome in cutaneous melanoma. Epigenetics 2010; 6: 388-394.

36. Han YC, Park CY, Bhagat G, Zhang J, Wang Y, Fan JB et al. microRNA-29a induces aberrant self-renewal capacity in hematopoietic progenitors, biased myeloid development, and acute myeloid leukemia. J Exp Med 2010; 207: 475-489.

37. Francy JM, Nag A, Conroy EJ, Hengst JA, Yun JK. Sphingosine kinase 1 expression is regulated by signaling through $\mathrm{PI} 3 \mathrm{~K}, \mathrm{AKT} 2$, and $\mathrm{mTOR}$ in human coronary artery smooth muscle cells. Biochim Biophys Acta 2007; 1769: 253-265. 
38. Li X, Leu S, Cheong A, Zhang H, Baibakov B, Shih C et al. Akt2, phosphatidylinositol 3-kinase, and PTEN are in lipid rafts of intestinal cells: role in absorption and differentiation. Gastroenterology 2004; 126: 122-135.

39. Liu AX, Testa JR, Hamilton TC, Jove R, Nicosia SV, Cheng JQ. AKT2, a member of the protein kinase $B$ family, is activated by growth factors, v-Ha-ras, and v-src through phosphatidylinositol 3-kinase in human ovarian epithelial cancer cells. Cancer Res 1998; 58: 2973-2977.

40. Decker T, Schneller F, Hipp S, Miething C, Jahn T, Duyster J et al. Cell cycle progression of chronic lymphocytic leukemia cells is controlled by cyclin D2, cyclin D3, cyclin-dependent kinase (cdk) 4 and the cdk inhibitor p27. Leukemia 2002; 16: 327-334.

41. Wang L, Wang J, Blaser BW, Duchemin AM, Kusewitt DF, Liu T et al. Pharmacologic inhibition of CDK4/6: mechanistic evidence for selective activity or acquired resistance in acute myeloid leukemia. Blood 2007; 110: 2075-2083.

42. Chang TC, Yu D, Lee YS, Wentzel EA, Arking DE, West KM et al. Widespread microRNA repression by Myc contributes to tumorigenesis. Nat Genet 2008; 40: 43-50.

43. Mott JL, Kurita S, Cazanave SC, Bronk SF, Werneburg NW, Fernandez-Zapico ME Transcriptional suppression of mir-29b-1/mir-29a promoter by c-Myc, hedgehog, and NF-kappaB. J Cell Biochem 2010; 110: 1155-1164.

44. Zhang X, Zhao X, Fiskus W, Lin J, Lwin T, Rao R et al. Coordinated silencing of MYCmediated miR-29 by HDAC3 and EZH2 as a therapeutic target of histone modification in aggressive B-Cell lymphomas. Cancer Cell 2012; 22: 506-523.
45. Park SY, Lee JH, Ha M, Nam JW, Kim VN. MiR-29 miRNAs activate p53 by targeting p85 alpha and CDC42. Nat Struct Mol Biol 2009; 16: 23-29.

46. Pekarsky Y, Santanam U, Cimmino A, Palamarchuk A, Efanov A, Maximov V et al. Tcli expression in chronic lymphocytic leukemia is regulated by miR-29 and miR-181. Cancer Res 2006; 66: 11590-11593.

47. Tumaneng $\mathrm{K}$, Schlegelmilch $\mathrm{K}$, Russell $\mathrm{RC}$, Yimlamai $\mathrm{D}$, Basnet $\mathrm{H}$, Mahadevan $\mathrm{N}$ et al. YAP mediates crosstalk between the Hippo and $\mathrm{PI}(3) \mathrm{K}-\mathrm{TOR}$ pathways by suppressing PTEN via miR-29. Nat Cell Biol 2012; 14: 1322-1329.

48. Xu Q, Simpson SE, Scialla TJ, Bagg A, Carroll M. Survival of acute myeloid leukemia cells requires PI3 kinase activation. Blood 2003; 102: 972-980.

49. Li L, Sarver AL, Alamgir S, Subramanian S. Downregulation of microRNAs miR-1, -206 and -29 stabilizes PAX3 and CCND2 expression in rhabdomyosarcoma. Lab Invest 2012; 92: $571-583$.

50. Trang $\mathrm{P}$, Wiggins JF, Daige $\mathrm{CL}$, Cho $\mathrm{C}$, Omotola M, Brown D et al. Systemic delivery of tumor suppressor microRNA mimics using a neutral lipid emulsion inhibits lung tumors in mice. Mol Ther 2011; 19: 1116-1122.

51. Kota J, Chivukula RR, O'Donnell KA, Wentzel EA, Montgomery CL, Hwang HW et al. Therapeutic microRNA delivery suppresses tumorigenesis in a murine liver cancer model. Cell 2009; 137: 1005-1017.

52. Rossi JJ. New hope for a microRNA therapy for liver cancer. Cell 2009; 137: 990-992.

53. Chen C, Ridzon DA, Broomer AJ, Zhou Z, Lee DH, Nguyen JT et al. Real-time quantification of microRNAs by stem-loop RT-PCR. Nucleic Acids Res 2005; 33: e179.

Supplementary Information accompanies this paper on Cell Death and Differentiation website (http://www.nature.com/cdd) 